DIVISION OF THE HUMANITIES AND SOCIAL SCIENCES

CALIFORNIA INSTITUTE OF TECHNOLOGY

PASADENA, CALIFORNIA 91125

\title{
Candidate entry and political polarization: An experimental study
}

Jens Grober

Florida State University

Thomas R. Palfrey

Caltech

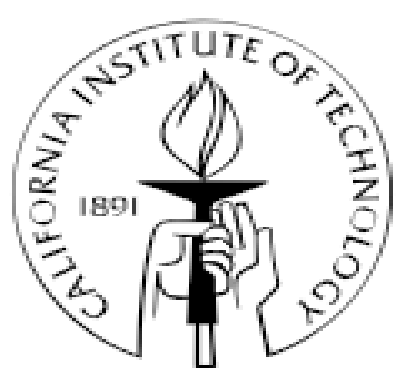

SOCIAL SCIENCE WORKING PAPER 1427

December 2016 


\title{
Candidate entry and political polarization: An experimental study*
}

\author{
Jens Großer (Florida State University)a \\ Thomas R. Palfrey (California Institute of Technology) ${ }^{\mathrm{b}}$
}

December 14, 2016

\begin{abstract}
We report the results of a laboratory experiment based on a citizen-candidate model with private information about ideal points. Inefficient political polarization is observed in all treatments; that is, citizens with extreme ideal points enter as candidates more often than moderate citizens. Second, less entry occurs, with even greater polarization, when voters have directional information about candidates' ideal points, using ideological party labels. Nonetheless, this directional information is welfare enhancing because the inefficiency from greater polarization is outweighed by lower total entry costs and better voter information. Third, entry rates are decreasing in group size and the entry cost. These findings are all implied by properties of the unique symmetric Bayesian equilibrium of the entry game. Quantitatively, we observe too little (too much) entry when the theoretical entry rates are high (low). This general pattern of observed biases in entry rates is implied by logit quantal response equilibrium.
\end{abstract}

\footnotetext{
${ }^{*}$ We would like to thank participants at the Public Policy and Social \& Economic Behavior conference, University of Cologne, the $1^{\text {st }}$ Southwest Experimental and Behavioral Economics (SWEBE) conference, UC Irvine, and the North-American ESA meeting in Tucson, and at seminars at Caltech and the Hertie School of Governance, Berlin for their helpful comments. We are also grateful for financial support from the CEC-COFRS Award, Florida State University. Palfrey acknowledges support from NSF (SES-1426560), the Gordon and Betty Moore Foundation (SES-1158), and a Russell Sage Foundation Visiting Scholar Fellowship (2014-15),

a Departments of Political Science and Economics, Florida State University, Tallahassee, FL-32306, jgrosser@fsu.edu

b Division of the Humanities and Social Sciences, California Institute of Technology, Pasadena, CA-91125, trp@hss.caltech.edu
} 


\section{Introduction}

Who runs for office? How many candidates can we expect to compete in a winner-take-all election? Are those who run for political office representative of the views of the general polity? How might entry depend upon the role of political organizations, such as parties, in the selection of candidates? Here, we examine these and related questions in a laboratory experiment by testing predictions derived from a citizen-candidate entry game and comparing entry behavior across several different environments. The citizen candidate model, which originates in Besley and Coate (1997) and Osborne and Slivinski (1996), departs from the canonical spatial model of electoral competition with exogenous politicians (Downs 1957; Hotelling 1929) in two important ways. ${ }^{1}$ First, the candidates are citizens with policy preferences (as in Wittman 1983) who vote in the election and, once elected, implement their own taste as the common policy. Second, the voting stage is preceded by an entry stage where each citizen decides whether to throw her hat in the ring. Thus, a citizen's objective function not just takes into account the benefits of holding office ("spoils of office") as in the canonical model, but is also includes the cost of candidacy and the indirect benefit of reducing the possibility of less desired policies that would be implemented by other potential candidates. Because the citizens themselves decide on whether to run for office, both the number and the ideological composition of entering candidates are modeled as equilibrium outcomes. Crucially, their entry decisions are asymmetric since citizens with different policy preferences will anticipate different benefits from policy implementation. Coordination problems are also present due to nontrivial strategic uncertainties.

In the standard citizen candidate model, all citizens are endowed with complete information about the exact location of all others' ideal points, and hence can infer the exact location of each entering candidate. However, many empirical studies indicate that citizens tend to have limited knowledge about the candidates' exact stances on policy issues (e.g., Campbell et al. 1960; Palfrey and Poole 1987). We can think of various reasons why this is the case. For example, time and willpower is scarce so that many citizens simply cannot be as well informed about the policy intentions of candidates as, say, special interest groups. Or, politicians often remain quiet about their true intentions during campaigns due to strategic incentives and it is almost impossible for citizens to discover these tastes, even if they are willing to exert effort. More realistically, citizens have only

\footnotetext{
1 The citizen candidate approach has its roots in work on policy-motivated candidates (e.g., Wittman 1983), strategic entry (e.g., Feddersen, Sened, and Wright 1990; Palfrey 1984), and Duverger's law (e.g., Feddersen 1992; Palfrey 1989). For a survey of citizen candidate models, see Bol, Dellis, and Oak (2015).
} 
incomplete information about the location of the entering candidates, and this leads us to adopt a Bayesian game formulation of the entry game.

The experiment is based on a laboratory implementation of the following citizen-candidate entry game with incomplete information (Großer and Palfrey 2014). An electorate consisting of $n$ citizens is electing a leader to implement a policy outcome by plurality voting. Each citizen has a privately known ideal point in a one dimensional policy space. These ideal points are iid draws from a commonly known, uniform distribution over the policy space. A citizen's utility from the policy outcome declines linearly in the absolute distance from her ideal point. The game has two decisionmaking stages. In the first stage (Entry), citizens decide independently and simultaneously whether and pay a $\operatorname{cost} c>0$ to become a candidate in the election, or not enter and bear no cost. In the second stage (Voting), each citizen casts a vote for exactly one of the candidates. In the baseline model citizens must vote without any additional information about the candidates' ideal points (of course, the contenders know their own ideal point). The candidate with the most votes becomes the leader and receives a bonus $b>0$ (i.e., the spoils of office) and her ideal point is automatically implemented as the common policy. Ties are broken randomly. Finally, if nobody enters, then a leader is randomly selected from all the citizens and her ideal point is implemented as the common policy.

Because symmetric BNE in cutpoint strategies is unique, potentially difficult issues of equilibrium selection are avoided. By contrast, citizen candidate models with complete information about candidate ideal points (e.g., Besley and Coate 1997; Osborne and Slivinski 1996) usually have multiple equilibria, and therefore are more complicated to evaluate empirically even in the lab. A second advantage of the incomplete information approach is that distributional predictions are qualitative predictions about polarization and the number of entrants is more robust to a wide range of environmental parameters one expects to encounter in the field. In fact, existing empirical evidence strongly suggests that policy preferences of politicians are more polarized than the citizens they represent (e.g., Bafumi and Herron 2010; DiMaggio, Evans, and Bryson 1996; Fiorina, Abrams, and Pope 2006; McCarty, Poole, and Rosenthal 2006). Beyond this empirical support, our approach offers a theoretical foundation for possible mechanisms that can lead to political polarization. The experiment provides additional evidence by generating data on entry behavior in carefully controlled environments, in order to assess the plausibility of these theoretical mechanisms.

This citizen-candidate entry game with incomplete information yields sharp predictions about the distribution of the entrants' ideal points and the rate of entry. The key property of equilibrium is political polarization in the sense that candidate entry is from the extremes of the policy space, contrary to usual centrist predictions of most models of political competition. 
Specifically, the unique symmetric Bayesian Nash equilibrium (BNE) in the baseline entry game consists of a left and right cutpoint, $\left(\breve{x}_{l}, \breve{x}_{r}\right)$, where each citizen with an ideal point at either cutpoint or to the left of $\breve{x}_{l}$ or to the right of $\breve{x}_{r}$ enters the political competition, while every citizen with an ideal point between the two cutpoints doesn't enter. ${ }^{2}$ Based on this equilibrium, one can also compute expected economic welfare and its various components, and derive comparative statics predictions of interest such as the effects of electorate size, entry costs, benefits of holding office, and the distribution of ideal points on entry decisions and welfare.

The intuition for why asymmetric information about citizen and candidate ideal points creates political polarization can be explained by a simple example. Suppose, for example, the policy space is $[-1,1]$ and there are three entrants with ideal points at $-1,0$, and 1 , respectively. Then, each candidate has a one-third chance of winning the election (i.e., they each vote for themselves and, because ideal points are private information, each non-candidate votes randomly for one of them). With identical entry costs and office-holding benefits, they only differ in their expected policy losses if a rival candidate happens to win. In our example, for each of the two extreme candidates the expected loss equals 1 , while the expected loss is only $2 / 3$ for the moderate candidate. This illustrates what turns out to be a general property of the model: extreme citizens have a stronger incentive to enter the political competition than moderate citizens, and is the basis for the emergence of political polarization in the model. This result holds more generally for any smooth probability distribution of ideal points (Großer and Palfrey 2014) and weakly concave preferences of voters. Importantly, polarization is welfare reducing since ex ante the expected total policy loss is minimized when the common policy is a centrist ideal point.

While incomplete information is surely an important consideration in elections, the model described above explores a polar case where citizens are completely uninformed about the candidates' ideal points, except for the inference they can make from equilibrium strategies, to wit, that entry comes from the extremes. It is interesting to explore an intermediate case of incomplete information that also corresponds to the widely observed phenomenon that ideologically-based parties act as gatekeepers in the candidate entry stage. As a result most citizens are aware of the party affiliations of candidates, which are for example communicated via nominating conventions, and since parties are ideological they can use this crucial piece of information as a credible cue about a candidate's ideal point, for their voting decision (e.g., Ansolabehere, Rodden, and Snyder 2008; Snyder and Ting 2002).

\footnotetext{
2 In the Voting stage, each candidate optimally votes for herself and each non-candidate optimally votes randomly for a candidate. The expected policy outcome does not change if abstention is allowed.
} 
To account for relevant party cues, we extend the basic citizen-candidate entry game where a left and a right party each nominates a candidate from the pool of entrants on their side of the political spectrum, and citizens are informed about each nominee's party affiliation. This provides some useful voting information, although the exact ideal points of the party nominees are not revealed. This "directional information" has two important effects. First, it leads to fewer and even more polarized entrants than in the absence of parties. This is because a citizen always votes for her preferred party nominee so, availing the own vote, her updated belief that this nominee prevails in the election is greater than 50 percent for our symmetric distribution of ideal points (cf. Goeree and Großer 2007). As a consequence, ceteris paribus, the probability of becoming the leader is greater with than without parties (we assume that each entrant is equally likely her party's nominee) which, in equilibrium, translates into a lower incentive to run for office, more extreme cutpoints, and thus fewer entrants. Second, political parties enable implicit vote coordination; that is, citizens vote for the nominee whose ideal point is from the same direction as the own one. Importantly, such coordination is welfare enhancing in expectation since the majority party is more likely to win. Notice that while the majority can sometimes also be defeated if none of its citizens runs for office, this must not be inefficient as they are all more moderate than the respective cutpoint. Overall, in expectation, political parties raise welfare since the lower total entry expense and greater chances of the majority party outweigh the greater total policy loss caused by more extreme leaders.

By including treatments both with and without political parties, our experiment offers a clean test of the hypothesis that party-organized elections increase political polarization on average but at the same time do not reduce welfare. The experiment also varies the environment in two other dimensions: electorate size and entry cost. Both of these have intuitive qualitative effects, that is, expected entry rates (i.e., entry as a fraction of the electorate size) decrease in both electorate size and entry cost. The decrease in entry rates arises from the equilibrium cutpoints becoming more extreme, which immediately implies that political polarization is increasing in both the electorate size and the entry cost.

Looking ahead at the results briefly, in all treatments conducted in the experiment, we observe the key polarization effect: the probability of candidate entry is increasing in the distance between the median and a citizen's ideal point. All of the model's primary comparative static properties of entry behavior find support in the data. And, all the model's primary comparative static properties about welfare are also supported. Quantitatively, relative to the theoretical equilibrium, we observe higher rates of entry for those treatments where entry is predicted to be below 50 percent and weakly lower entry rates for those treatments where predicted entry is above 50 
percent. This pattern of departure from BNE is consistent with past experiments on entry in much different settings (see Goeree and Holt 2005) and is a general property of regular quantal response equilibrium in these games (Goeree, Holt and Palfrey 2005, 2016).

\section{Related literature}

We are aware of just three other citizen candidate experiments, which all study plurality elections with complete information about candidate ideal points and vary the entry cost (Cadigan 2005; Elbittar and Gomberg 2009; Kamm 2016).3 Specifically, Cadigan (2005) uses a pen-and-paper experiment with electorates of five participants who have distinct ideal points and independently and simultaneously decide on whether to become a candidate. The electoral composition and ideal points are constant throughout, but after each election ideal points are reallocated among the participants. Further, participants automatically vote sincerely for the candidate nearest to the own location to select the leader, who receives a bonus and whose ideal point is declared the common policy. If nobody enters, then one participant is randomly appointed the leader. Elbittar and Gomberg (2009) and Kamm (2016) employ setups similar to the one just described, but a few differences are worth mentioning. For example, their experiments are computerized and sincere votes are exclusively cast by an infinite number of non-candidate robots with uniformly distributed ideal points over the continuum $[0,100]$. Also, Elbittar and Gomberg use electorates of three or five participants located at three feasible policies, and the default policy if none of them enters is that all must pay a large penalty. ${ }^{4}$ We can summarize the three main common results of these citizen candidate experiments as follows. First, there are more candidates on average when the entry cost is lower. Second, relative to Nash equilibrium (NE), there is over-entry on average. Third, the qualitative predictions of entry are mostly supported by the data and some learning towards equilibrium play is observed. Looking more closely at their results, if the entry cost is high the unique $\mathrm{NE}$ is that only the median citizen enters (Elbittar and Gomberg have two equilibria, each where one of two median citizens enters). The median participant does indeed enter often but, against the

\footnotetext{
3 Our study is also related to simpler entry experiments. For example, Fischbacher and Thöni (2008) examine a winnertake-all market where a monetary prize goes to a randomly selected entrant, and the expected amount falls in the number of entrants. They find over-entry relative to Nash equilibrium, and more severe so in larger groups. Or, Camerer and Lovallo (1999) find under-entry with asymmetric, randomly allocated rank-based payoffs. Both studies contain features also present in our work, namely, the probability of getting the bonus falls in the number of entrants and expected payoffs are asymmetric due to various different ideal points. Finally, Goeree and Holt (2005) use quantal response equilibrium (McKelvey and Palfrey 1995, 1998) to make sense of both over- and under-entry in various entry experiments.

${ }^{4}$ In the citizen candidate model a default policy is necessary to ensure that a common policy is executed in equilibrium. But out-of-equilibrium play occurs in the lab and in Elbittar and Gomberg (2009) the penalty resulted in bankruptcy of some participants. See Großer and Palfrey (2014) for a discussion of different default policies.
} 
prediction, so do her or his immediate neighbors (albeit to a much lesser extent in Cadigan). By contrast, two equilibria arise for a low entry cost, one with only the median citizen entering and one with the median's immediate neighbors entering (again, Elbittar and Gomberg have multiple such equilibria). However, in the experiments coordination on one of these pure strategy equilibria usually doesn't occur. Next, in addition to plurality elections Elbittar and Gomberg (2009) study run-off elections and Kamm (2016) examines proportional representation. Elbittar and Gomberg observe a predicted shift in average entry towards the median in run-off elections relative to plurality voting. Kamm adopts proportional representation à la Hamlin and Hjortlund (2000), where the common policy is the vote-weighted average of the candidate ideal points and the leader bonus is given to the contender with most votes (ties are broken randomly). As predicted, he finds more polarized entry than with plurality voting. Although we too explore plurality voting and how the entry cost affects the decision to run for office, our study is very different from these other citizen candidate experiments. In particular, we explore incomplete information about candidate ideal points, as opposed to the complete information they study, which yields mostly unique distributional predictions of who enters. And, we also present the first citizen candidate experiment examining how parties and electorate size influence political polarization and welfare.

\section{The model}

We adapt the Großer and Palfrey (2014) citizen candidate model with a continuous policy space for the case of a discrete policy space, which is implemented in the experiment. An electorate of $n$ citizens is electing a leader to implement a common policy $\gamma$ from the set $\Gamma=\{1,2, \ldots, 100\}$. Each citizen $i$ has a privately known ideal point $x_{i}$ that is an iid draw from a uniform distribution also over $\Gamma$, where $i$ 's payoff from the policy outcome, $v\left(x_{i}, \gamma\right)=-\left|x_{i}-\gamma\right|$, is linearly decreasing in the absolute distance between her ideal point and the policy outcome, $\gamma$.

\subsection{Equilibrium without parties}

We first describe and analyze the case where there are no parties. In the first stage (Entry), citizens independently and simultaneously decide whether to enter as a candidate and pay a cost $c>0$, or not enter and bear no cost. In the second stage (Voting), each citizen (including each of the entrants) votes for one of the candidates, possibly herself. The candidate with the most votes is elected and receives an office holding benefit of $b \geq 0$. Ties are broken randomly. If no citizen enters, then a default policy, $d$, takes effect, randomly selecting one citizen as the leader who receives $b$ but does not pay $c$. The leader's ideal point is implemented as the policy outcome. Summarizing, the total payoff of citizen $i$ is given by 


$$
\pi_{i}\left(x_{i}, \gamma, e_{i}, w_{i}\right)=K-\left|x_{i}-\gamma\right|-e_{i} c+w_{i} b,
$$

where $K$ is a constant, $e_{i}=1$ if she entered ( $e_{i}=0$ otherwise) and $w_{i}=1$ if she is the leader $\left(w_{i}=0\right.$ otherwise). We assume citizen $i$ is risk neutral and maximizes the expected value of $\pi_{i}$.

The perfect Bayesian equilibrium (PBE) of our citizen candidate game has the following properties. ${ }^{5}$ In the Voting stage, each candidate votes for herself and each non-candidate votes randomly with equal probability for one of the contenders. In the symmetric BNE of the Entry stage each citizen $i$ follows the cutpoint strategy

$$
\check{e}_{i}=\left\{\begin{array}{lll}
0 & \text { if } & x_{i} \in\left\{\check{x}_{l}+1, \ldots, \check{x}_{r}-1\right\} \\
1 & \text { if } \quad x_{i} \in\left\{1, \ldots, \check{x}_{l}\right\} \cup\left\{\check{x}_{r}, \ldots, 100\right\}
\end{array}\right.
$$

where $\left(\check{x}_{l}, \breve{x}_{r}\right)$ is an ideal point pair with $1 \leq \check{x}_{l} \leq 50$ and $\check{x}_{r}=101-\check{x}_{l} \cdot{ }^{6}$ That is, the cutpoint strategy $\check{e}_{i}$ dictates that each citizen with an ideal point at or more "extreme" than $\check{x}_{l}$ or $\check{x}_{r}$ runs for office, and each citizen with an ideal point more "moderate" than $\check{x}_{l}$ and $\check{x}_{r}$ does not run. The equilibrium cutpoints are derived by comparing a citizen's expected payoffs for entering and not entering, given that other individuals are using such cutpoints (see appendix for details). For the specification assumed here, if all other citizens $j \neq i$ are using cutpoint strategy $\left(\check{x}_{l}, \breve{x}_{r}\right)$, the optimal entry strategy of a citizen type $x_{i}$ is to enter if and only if

$$
\begin{aligned}
(1-p)^{n-1}\left(\frac{n-1}{n}\right)\left[b+E\left[v\left(x_{i}, d\right) \mid d \in\left\{\check{x}_{l}+1, \ldots, \check{x}_{r}-1\right\}\right]\right] \\
\quad+\sum_{m=2}^{n}\left(\begin{array}{c}
n-1 \\
m-1
\end{array}\right) p^{m-1}(1-p)^{n-m} \frac{1}{m}\left[b+E\left[v\left(x_{i}, \gamma\right) \mid \gamma \notin\left\{\check{x}_{l}+1, \ldots, \check{x}_{r}-1\right\}\right]\right] \geq c,
\end{aligned}
$$

where the left-hand side $(L H S$ ) gives the difference between the expected benefit from entering and expected benefit from not entering, excluding the cost of entry, which appears on the right-hand side $(R H S)$. We use the notation $m \equiv \sum_{i=1}^{n} e_{i}$ to denote the number of entrants and $p$ to denote the ex-ante probability that a randomly selected citizen $j \neq i$ enters. If nobody enters, then the default policy $d$ takes effect, where the expected loss from the absolute distance in citizen $i$ 's ideal point and the common policy, or policy loss, is given by

$$
E\left[v\left(x_{i}, d\right) \mid d \in\left\{\check{x}_{l}+1, \ldots, \check{x}_{r}-1\right\}\right]=\frac{1}{1-p} \sum_{x=\check{x}_{l}+1}^{\breve{x}_{r}-1} \frac{\left|x_{i}-x\right|}{100},
$$

\footnotetext{
${ }^{5}$ For details see Appendix A and Großer and Palfrey (2014).

6 The symmetry of the cutpoints around the median ideal point arises because the uniform distribution of ideal points is symmetric around the median. In general, the cutpoints can be asymmetrically located if the distribution is asymmetric. See Großer and Palfrey (2014) for details.
} 
and if at least one citizen $j \neq i$ enters, the respective expected policy loss is given by

$$
E\left[v\left(x_{i}, \gamma\right) \mid \gamma \notin\left\{\check{x}_{l}+1, \ldots, \check{x}_{r}-1\right\}\right]=\frac{1}{p}\left[\sum_{x=1}^{\check{x}_{l}} \frac{\left|x_{i}-x\right|}{100}+\sum_{x=\check{x}_{r}}^{100} \frac{\left|x_{i}-x\right|}{100}\right] .
$$

The LHS of (3) has a straightforward interpretation. The first term corresponds to the event that no citizen $j \neq i$ enters, which occurs with probability $(1-p)^{n-1}$. The intuition is that if only citizen $i$ enters, then she can ensure leadership by entering and so receives $b$ and avoids an expected loss (4) from someone else's policy decision. Note that if $i$ does not enter, these two payoffs accrue with probability $1 / n$ and $(n-1) / n$, respectively, due to the specification of the stochastic default policy, $d$. The second term on the LHS of (3) represents the event where at least one other citizen $j$ enters. For each possible number of entrants $m \geq 2$, including herself, citizen $i$ both receives $b$ and avoids a loss from policy with probability $1 / \mathrm{m}$. The expected policy loss is different depending on whether the leader's ideal point is in the same direction as $i$ 's ideal point, which is captured by the two terms in brackets in (5). Finally, our experimental parameters yield interior equilibrium entry cutpoints, which is computed by setting $x_{i}=\breve{x}_{l}$ and $\check{x}_{r}=\breve{x}_{l}$ and then solving (3) at equality.

\subsection{Equilibrium with parties}

In elections where the entry stage is organized by ideological political parties, the two decisionmaking stages have the following differences. First, all citizens with an ideal point $x \in\{1, \ldots, 50\}$ $(\{51, \ldots 100\})$ automatically belong to the Left (Right) Party. If one or more citizens from a party choose to enter, then one of them becomes the party nominee in the election. For simplicity we assume each candidate from the party is selected as the party's nominee with equal probability. The party affiliation of each nominee, albeit not exact ideal point, is then revealed to all citizens. Further, each citizen votes for a nominee, possibly herself. If only one party has a nominee, everyone must vote for her. If nobody enters, then the default policy $d$ is activated. As in the case with no parties, the chosen leader's ideal point is implemented as the policy outcome.

The PBE of the citizen candidate game with parties has the following structure. In the Voting stage, each nominee votes for herself and each non-nominee, entrant or not, votes for the nominee who yields her the highest expected payoff. This will be the nominee from their own party (whose ideal point is expected to be closer to the own taste), if there is one. In the symmetric BNE equilibrium of the Entry stage each citizen follows a cutpoint strategy as in (2). Analogous to expression (3), the optimal entry strategy of a citizen with ideal point $x_{i}$ in the Right Party is to enter if and only if (and similar for a citizen in the Left Party): 


$$
\begin{aligned}
(1-p)^{n-1}\left(\frac{n-1}{n}\right)\left[b+E\left[v\left(x_{i}, d\right) \mid d \in\left\{\check{x}_{l}+1, \ldots, \check{x}_{r}-1\right\}\right]\right] \\
+\sum_{m_{r}=2}^{n}\left(\begin{array}{c}
n-1 \\
m_{r}-1
\end{array}\right)\left(\frac{p}{2}\right)^{m_{r}-1}(1-p)^{n-m_{r}} \frac{1}{m_{r}}\left[b+E\left[v\left(x_{i}, \gamma\right) \mid \gamma \in\left\{\check{x}_{r}, \ldots, 100\right\}\right]\right] \\
+\sum_{m_{l}=1}^{n-1} \sum_{k=0}^{n-m_{l}-1}\left(\begin{array}{c}
n-1 \\
m_{l}
\end{array}\right)\left(\frac{p}{2}\right)^{m_{l}}(1-p)^{n-m_{l}-1}\left(\begin{array}{c}
n-m_{l}-1 \\
k
\end{array}\right)\left(\frac{1}{2}\right)^{n-m_{l}-1} \\
\quad \times \rho_{r}\left[b+E\left[v\left(x_{i}, \gamma\right) \mid \gamma \in\left\{1, \ldots, \check{x}_{l}\right\}\right]\right] \\
+\sum_{m_{r}=2}^{n-1} \sum_{m_{l}=1}^{n-m_{r}} \sum_{k=0}^{n-m}\left(\begin{array}{c}
n-1 \\
m_{r}-1
\end{array}\right)\left(\begin{array}{c}
n-m_{r} \\
m_{l}
\end{array}\right)\left(\frac{p}{2}\right)^{m_{r}-1}\left(\frac{p}{2}\right)^{m_{l}}(1-p)^{n-m}\left(\begin{array}{c}
n-m \\
k
\end{array}\right)\left(\frac{1}{2}\right)^{n-m} \\
\quad \times \frac{\rho_{r}}{m_{r}}\left[b+E\left[v\left(x_{i}, \gamma\right) \mid \gamma \in\left\{\check{x}_{r}, \ldots, 100\right\}\right]\right] \geq c .
\end{aligned}
$$

The ex-ante probability of a random citizen $j \neq i$ entering from either direction is denoted by $p$, and the number of entrants from the Left and Right Party is denoted by $m_{l}$ and $m_{r}$, respectively, with $m \equiv$ $m_{l}+m_{r}$. Also note that the probability a random citizen enters as Left Party candidate (or Right Party candidate) is $p / 2$ since the distribution of ideal points is uniform. The win probability of the Right Party is denoted by $\rho_{r}=H\left[\frac{m_{r}+k}{n}-\frac{1}{2}\right]$ with $H[z]= \begin{cases}0 & \text { if } \quad z<0 \\ 1 / 2 & \text { if } \quad z=0, \text { and the expected policy } \\ 1 & \text { if } z>0\end{cases}$ losses in the respective terms are given by

$$
\begin{aligned}
E\left[v\left(x_{i}, d\right) \mid d \in\left\{\check{x}_{l}+1, \ldots, \check{x}_{r}-1\right\}\right] & =\frac{1}{1-p} \sum_{x=\check{x}_{l}+1}^{\check{x}_{r}-1} \frac{\left|x_{i}-x\right|}{100} \\
E\left[v\left(x_{i}, \gamma\right) \mid \gamma \in\left\{1, \ldots, \check{x}_{l}\right\}\right] & =\frac{1}{p / 2} \sum_{x=1}^{\check{x}_{l}} \frac{\left|x_{i}-x\right|}{100} \\
E\left[v\left(x_{i}, \gamma\right) \mid \gamma \in\left\{\check{x}_{r}, \ldots, 100\right\}\right] & =\frac{1}{p / 2} \sum_{x=\check{x}_{r}}^{100} \frac{\left|x_{i}-x\right|}{100}
\end{aligned}
$$

The first term on the LHS of (6) is the same as in (3) and represents the case where no citizen $j \neq i$ enters. The second term gives the cases where at least one $j$ also enters from the Right Party, but no one enters from the Left Party. In these events, citizen $i$ anticipates gains $b / m_{r}$ and, from policy loss avoidance, $1 / m_{r} \times E\left[v\left(x_{i}, \gamma\right) \mid \gamma \in\left\{\check{x}_{r}, \ldots, 100\right\}\right]$ because one of the $m_{r}$ Right Party entrants is randomly appointed the nominee of this party. The third term on LHS(6) gives the cases where at least one citizen $j \neq i$ enters from the Left Party, but only citizen $i$ enters from the Right Party, 
so $m_{r}=1$ and she secures the Right Party nomination. Due to symmetry, each of the $n-m_{l}-1$ nonentrants with ideal points strictly within the equilibrium cutpoint pair prefers the Left or Right Party nominee with probability one-half for each, and votes accordingly (as accounted for by the index $k$ of the summation). Since citizen $i$ is in the Right Party, her expected net gains from entry are $\rho_{r} b$ and $\rho_{r} E\left[v\left(x_{i}, \gamma\right) \mid \gamma \in\left\{1, \ldots, \check{x}_{l}\right\}\right]$ (i.e., the policy loss avoided if the opponent nominee runs unopposed). Note that $\rho_{r}$ declines with each Left Party entrant, who is expected to vote for this party's nominee. The fourth term of the LHS of (6) represents the cases where at least one citizen $j \neq$ $i$ enters from each direction, which yields a mix of the second and third terms. Finally, our experimental parameters yield interior equilibrium entry cutpoints characterized by solutions to (6), at equality.

\section{Experimental design}

The experiment was conducted at the Experimental Social Science Laboratory at Florida State University. ${ }^{7}$ A total of 148 students participated in eight sessions of 16 or 20 participants each, with each session lasting about 1.5 hours. Earnings were expressed in points and exchanged for cash for $\$ 1$ per 250 points at the end of a session. Participants earned on average \$22.91, including \$7 for showing up.

In a $2 \times 2 \times 2$ treatment design, we varied the "entry cost" ( $c=10$ and 20 points) within subjects and "group size" ( $n=4$ and 10) and "party mode" ( $\theta=$ No Party and Party) between subjects. Each session had two parts of 30 decision periods each, where the entry cost changed from one part to the next and the cost order changed across sessions. Participants knew there are two parts, but were instructed about the second part only after completing the first one. In all treatments, at the start of each period the subject pool was randomly divided into separate 4- or 10-person groups that did not interact with one another in this period, and each participant received a new ideal point and, entirely independently, a new letter ID label. They were informed that ideal points are iid random draws from a uniform distribution over the integers $\{1,2, \ldots, 100\}$ and private information (i.e., not shown to others), and that letter IDs are iid draws from a uniform distribution over the whole alphabet and revealed to everyone in the group (albeit the participant behind a letter ID remained anonymous). In a given group and period different individuals could have the same ideal point but never the same letter ID.

Each period consisted of two consecutive stages where the participants independently and simultaneously made their decisions without communication. In the Entry stage, each group member

\footnotetext{
7 The software was programmed as server/client applications in Java, using the experimental open source package Multistage (http://multistage.ssel.caltech.edu:8000/multistage/). To recruit participants, we used ORSEE (Greiner 2015).
} 
decided on whether to enter the political competition and pay $c$ points, or not enter and bear no cost. In the Voting stage, in No Party the letter ID for each (independent) candidate was displayed on the computer screen with a button labeled with her or his letter ID (a candidate's own label was highlighted in red). In Party, one of the entrants with an ideal point $x_{i} \in\{1, \ldots, 50\}(\{51, \ldots, 100\})$ was randomly selected as the Left (Right) Party nominee, with equal probability for each, and a lone entrant was the nominee outright. If nobody entered from a party, then the party had no nominee. Each nominee was displayed on the computer screen with a button labeled with her or his letter ID (a nominee's own label was highlighted in red). ${ }^{8}$ Thus, everyone was informed that a nominee's ideal point is from the left or right subset of ideal points, but the exact location was not revealed. Next, each participant voted by clicking one of the candidate or nominee buttons and could not abstain. ${ }^{9}$ Candidates and nominees were not forced to vote for themselves. The candidate or nominee with the most votes was appointed the leader and received a bonus of $b=5$ points, with ties broken randomly. If nobody entered, then one participant was randomly and equiprobably appointed the leader (and received $b=5$ points but did not pay $c$ ). Either way, the leader's ideal point was implemented as the policy outcome. After the election, everyone was informed about the number of votes for each candidate or nominee, the leader's letter ID, the policy outcome, the own period earnings, and reminded whether she or he entered and was a leader (and thus paid $c$ and received b). ${ }^{10}$ In addition, the bottom of the screen contained a history panel where at any time participants could view this information from all previous periods. Participants were paid for all $2 \times 30=60$ periods. One unpaid practice round was conducted to familiarize them with the user interface. ${ }^{11}$

Table 1 summarizes our experimental design (first six columns) and quantitative BNE predictions of the relevant observable variables (last five columns; denoted by an asterisk and subscript $e$ for expected values). Each treatment $(n, c, \theta)$ has a unique symmetric cutpoint pair $\left(\check{x}_{l}^{*}, \check{x}_{r}^{*}\right)$ that determines the individual entry probability, $p^{*}$ (and thus the expected number of

\footnotetext{
8 In the experiment, a participant's ideal point was termed "your best outcome." In Party, we labeled left and right as "low number" and "high number" and citizens and nominees as "low/high number members" and "low/high number candidates," respectively. Also, with two nominees the button of the Left Party nominee was always to the left of the opponent's button. In No Party, "candidate" buttons were centered and ordered randomly from left to right, independent of letter IDs. In fact, in a group and period different participants could see different ID orderings.

${ }^{9}$ Since in theory non-nominees in Party strictly prefer voting to abstaining while non-candidates in No Party are indifferent between the two options, we chose mandatory voting to keep the No Party and Party designs as similar as possible. Future experiments can explore voluntary voting.

10 While the leader's exact ideal point was always revealed by the policy outcome, we did not disclose anyone else's ideal point. However, in Party with two nominees their vote tallies indicated, albeit somewhat imperfectly due to unexpected voting in the lab, how many ideal points were from the left and right direction, respectively. We chose to give participants relatively little feedback in order to keep the experimental design closer to the theory.

11 The online supporting material includes instructions and sample screenshots of the computer display. Due to a minor programming error that we learned about only after all the data was collected, the ideal point 100 never occurred. Our analysis of the data assumes that participants were unaware of this.
} 
entrants, $m_{e}^{*}$ ), for which we also compute the ex-ante expected individual payoff, $\pi_{e}^{*}=K-v_{e}^{*}-$ $p^{*} c+b / n$, where $K=100$ and $v_{e}^{*}$ denotes the expected policy loss.

Table 1: Experimental design and symmetric BNE predictions in the entry game

\begin{tabular}{|c|c|c|c|c|c|c|c|c|c|c|}
\hline \multirow[b]{2}{*}{$n$} & \multicolumn{5}{|c|}{ Design } & \multicolumn{5}{|c|}{ BNE predictions } \\
\hline & $C$ & Party & $\begin{array}{l}\text { \#Subjects } \\
\text { (Sessions) }\end{array}$ & $\begin{array}{c}\# \\
\text { Elections }\end{array}$ & \#Obs. & $\begin{array}{r}\text { Cutpoints } \\
{\left[\check{x}_{l}^{*}, \check{x}_{r}^{*}\right]}\end{array}$ & $p^{*}$ & $\pi_{e}^{*}$ & $v_{e}^{*}$ & $p^{*} c$ \\
\hline 4 & 10 & No & $36(2)$ & 270 & 1,080 & {$[42,59]$} & 0.84 & 66.98 & 25.87 & 8.40 \\
\hline 4 & 10 & Yes & $32(2)$ & 240 & 960 & {$[34,67]$} & 0.68 & 69.09 & 25.36 & 6.80 \\
\hline 4 & 20 & No & $36(2)$ & 270 & 1,080 & {$[20,81]$} & 0.40 & 64.59 & 28.66 & 8.00 \\
\hline 4 & 20 & Yes & $32(2)$ & 240 & 960 & {$[17,84]$} & 0.34 & 66.69 & 27.76 & 6.80 \\
\hline 10 & 10 & No & $40(2)$ & 120 & 1,200 & {$[21,80]$} & 0.42 & 59.71 & 36.59 & 4.20 \\
\hline 10 & 10 & Yes & $40(2)$ & 120 & 1,200 & {$[14,87]$} & 0.28 & 61.24 & 36.46 & 2.80 \\
\hline 10 & 20 & No & $40(2)$ & 120 & 1,200 & {$[10,91]$} & 0.20 & 57.59 & 38.91 & 4.00 \\
\hline 10 & 20 & Yes & $40(2)$ & 120 & 1,200 & {$[8,93]$} & 0.16 & 59.90 & 37.40 & 3.20 \\
\hline
\end{tabular}

Note: All sessions had two parts, each with a different entry cost for 30 periods. Each treatment used a leader bonus of $b=5$ points and a uniform distribution of ideal points over the integers $\{1,2, \ldots, 100\}$. Note that the two Party treatments with $c=10$ points have an additional BNE with two cutpoint pairs (see footnote 17).

\section{Hypotheses}

The first hypothesis captures the most important property of the BNE in the Entry game:

H1: Political Polarization. In every treatment, the entry rates are a weakly increasing function of the distance between ideal points and the median of the policy space.

The next four hypotheses specify the primary comparative statics derived based on BNE, from directly comparable pairs of treatments that differ only with respect to one variable (as compared to secondary qualitative predictions where treatments differ in two or three variables).

H2: Party Effect. Holding the entry cost and group size constant, expected equilibrium entry is lower with party-mediated elections than without parties. This implies four specific hypotheses in terms of pairwise comparisons for $p(n, c, \theta)$ (the effect is the same for $m_{e}(n, c, \theta)$ ):

$$
\begin{aligned}
& p^{*}(4,10, \text { No Party })>p^{*}(4,10, \text { Party }) ; \\
& p^{*}(4,20, \text { No Party })>p^{*}(4,20, \text { Party }) ; \\
& p^{*}(10,10, \text { No Party })>p^{*}(10,10, \text { Party }) ; \\
& p^{*}(10,20, \text { No Party })>p^{*}(10,20, \text { Party }) .
\end{aligned}
$$

H3: Size Effect. Holding the entry cost and party mode constant, in equilibrium, the probability of entry $p$ is decreasing in $n$. This gives four specific hypotheses in the form of pairwise comparisons for $p$ :

a) Entry probability:

$p^{*}(\mathbf{4}, 10$, No Party $)>p^{*}(\mathbf{1 0}, 10$, No Party); 


$$
\begin{aligned}
& p^{*}(\mathbf{4}, 20, \text { No Party })>p^{*}(\mathbf{1 0}, 20, \text { No Party }) \\
& p^{*}(\mathbf{4}, 10, \text { Party })>p^{*}(\mathbf{1 0}, 10, \text { Party }) \\
& p^{*}(\mathbf{4}, 20, \text { Party })>p^{*}(\mathbf{1 0}, 20, \text { Party })
\end{aligned}
$$

H4: Cost Effect. Holding the group size and party mode constant, expected equilibrium entry is decreasing in $c$, which implies four hypotheses in terms of pairwise comparisons for $p$ (the effect is the same for $m_{e}$ ):

$$
\begin{aligned}
& p^{*}(4,10, \text { No Party })>p^{*}(4,20, \text { No Party }) \\
& p^{*}(10,10, \text { No Party })>p^{*}(10,20, \text { No Party }) ; \\
& p^{*}(4, \mathbf{1 0}, \text { Party })>p^{*}(4,20, \text { Party }) \\
& p^{*}(10, \mathbf{1 0}, \text { Party })>p^{*}(10,20, \text { Party })
\end{aligned}
$$

H5: Welfare Effect. The hypotheses for equilibrium expected welfare, measured by expected individual payoffs, $\pi_{e}$, have the same signs as for $p$ in H3 (size effect) and H4 (cost effect), but the opposite signs in H2 (party effect).

a) Party:

$$
\begin{aligned}
& \pi_{e}^{*}(4,10, \text { No Party })<\pi_{e}^{*}(4,10, \text { Party }) \\
& \pi_{e}^{*}(4,20, \text { No Party })<\pi_{e}^{*}(4,20, \text { Party }) \\
& \pi_{e}^{*}(10,10, \text { No Party })<\pi_{e}^{*}(10,10, \text { Party }) \\
& \pi_{e}^{*}(10,20, \text { No Party })<\pi_{e}^{*}(10,20, \text { Party })
\end{aligned}
$$

c) Entry cost:

$$
\begin{aligned}
& \pi_{e}^{*}(4,10, \text { No Party })>\pi_{e}^{*}(4,20, \text { No Party }) ; \\
& \pi_{e}^{*}(10,10, \text { No Party })>\pi_{e}^{*}(10,20, \text { No Party }) ; \\
& \pi_{e}^{*}(4, \mathbf{1 0}, \text { Party })>\pi_{e}^{*}(4,20, \text { Party }) \\
& \pi_{e}^{*}(10, \mathbf{1 0}, \text { Party })>\pi_{e}^{*}(10,20, \text { Party })
\end{aligned}
$$

\section{b) Group size:} $\pi_{e}^{*}(4,10$, No Party $)>\pi_{e}^{*}(10,10$, No Party $) ;$ $\pi_{e}^{*}(4,20$, No Party $)>\pi_{e}^{*}(\mathbf{1 0}, 20$, No Party $) ;$ $\pi_{e}^{*}(4,10$, Party $)>\pi_{e}^{*}(\mathbf{1 0}, 10$, Party $)$; $\pi_{e}^{*}(4,20$, Party $)>\pi_{e}^{*}(10,20$, Party $)$.

As an even more stringent test of the equilibrium model, the BNE of the entry game also generates predictions about the complete order of qualitative predictions across all treatments, varying all the treatment variables simultaneously.

H6: Entry rate ordering. In equilibrium, the ordering of $p$ across all treatments is:

$$
\begin{gathered}
p^{*}(4,10, \text { No Party })>p^{*}(4,10, \text { Party })>p^{*}(10,10, \text { No Party })>p^{*}(4,20, \text { No Party })>p^{*}(4,20, \text { Party }) \\
>p^{*}(10,10, \text { Party })>p^{*}(10,20, \text { No Party })>p^{*}(10,20, \text { Party }) ;
\end{gathered}
$$

H7: Welfare ordering. In equilibrium, the ordering of $\pi_{e}$ across all treatments is:

$$
\begin{aligned}
\pi_{e}^{*}(4,10, \text { Party }) & >\pi_{e}^{*}(4,10, \text { No Party })>\pi_{e}^{*}(4,20, \text { Party })>\pi_{e}^{*}(4,20, \text { No Party })>\pi_{e}^{*}(10,10, \text { Party }) \\
& >\pi_{e}^{*}(10,20, \text { Party })>\pi_{e}^{*}(10,10, \text { No Party })>\pi_{e}^{*}(10,20, \text { No Party }) .
\end{aligned}
$$




\section{Experimental results: An examination of $\mathrm{H1}-\mathrm{H} 7$}

This section presents and analyzes the aggregate data as it relates specifically to the seven hypotheses listed above. In the next section, we take a deeper look at the individual level data.

\subsection{The polarization hypothesis (H1)}

The polarization hypothesis specifies that more extreme citizens are (weakly) more likely to enter as candidates. This is implied by the BNE of the entry game for all treatments in the experiment. An exact comparison of the data to the theory clearly rejects BNE, which makes the sharp prediction that entry rates should be either zero or one depending on whether a citizen's ideal point is sufficiently extreme. Of course the data is not discontinuous like this. Therefore, we fit a logit regression model of the probability of entry as a function of the distance of an ideal point from the median. Since this is a strategic game rather than a simple individual choice, so that if the players' entry functions are logit functions rather than strict cutpoint pairs, this in turn changes all of the players' responses in the game. Thus, we analyze the data using logit quantal response equilibrium of the game, or logit QRE (McKelvey and Palfrey 1995, 1998; Goeree, Holt, and Palfrey 2016).

QRE is a statistical generalization of NE that allows for decision-making errors that are systematic in the sense that more lucrative decisions are made more often than less lucrative decisions. In the logit specification of $\mathrm{QRE}$, the parameter $\lambda \geq 0$ represents the slope of the logit response function, with lower values indicating a flatter response ("higher error") and higher values indicate a steeper response. If $\lambda=0$, decisions are purely random so each citizen type $x \in\{1, \ldots, 100\}$ enters with probability one-half. The rationality level strictly rises in $\lambda$ until $\lambda \approx \infty$, where everyone is virtually fully rational and follows the BNE cutpoint strategy. In particular, each citizen type $x$ enters with probability $q(x) \in(0,1)$ strictly in between zero and one, which depends smoothly on the ideal point and is no longer a cutpoint strategy that dictates a "zero or one" binary choice for all $x$. This leads to a set of equilibrium conditions that are somewhat different from (2) to (9) (see Appendix A). The QRE entry probabilities are computed by simultaneously solving one-hundred different conditions, one for each possible $x .{ }^{12}$ Given these QRE entry probabilities as a function of $\lambda$, we estimate $\lambda$ by maximum likelihood. To avoid overfitting, the estimated parameter is constrained to be equal across all treatments. ${ }^{13}$

\footnotetext{
12 Note that $q(x)=q(101-x)$ in equilibrium due to our uniform distribution of ideal points, so we need only solve for fifty conditions. Also, we compute QRE entry probabilities assuming no errors in the Voting stage since unexpected votes are quite rare in the lab (as documented in the next section).

13 We also estimated the QRE model using an out-of-sample approach. Rather than constraining $\lambda$ to be constant across treatments, we estimated it separately for each treatment using only the odd-numbered periods, and then used those oddperiod estimates to compare predicted and actual values for the even-numbered periods. The conclusions are similar, and the in-sample fits for that alternative approach are significantly better.
} 
Table 2 shows for each treatment the observed entry rate, $p^{o b s}$, and the respective BNE and QRE entry rates (columns 4-6), where QRE entry rates are evaluated at the estimated value of $\lambda$. The theoretical predictions are exact, in the sense that they are based on the actual draws of ideal points realized in the experiment (i.e., empirical distribution), and hence are indicated by subscript emp, while still assuming that citizens respond to the theoretical uniform distribution. ${ }^{14}$ Importantly, the complete order of qualitative predictions across all treatments is preserved when changing to empirical BNE and QRE. The observed rates of entry are averaged over all periods and QRE predictions use $\hat{\lambda}=0.083$, the maximum likelihood estimate for all periods and treatments combined. Furthermore, the scatter plot in Figure 1 depicts for each treatment the BNE entry rate $p_{e m p}^{*}$ on the horizontal axis against the average observed rate $p^{o b s}$ (markers) and QRE rate $p_{e m p}^{\widehat{\lambda}}$ (markers linked by dotted line) on the vertical axis.

Table 2: Entry - Predictions and data

\begin{tabular}{rrr|rcc}
$n$ & $c$ & Party & $p^{o b s}$ & $p_{\text {emp }}^{*}$ & $p_{\text {emp }}^{\widehat{\lambda}}$ \\
\hline 4 & 10 & No & .687 & .844 & .602 \\
4 & 10 & Yes & .673 & .671 & .570 \\
4 & 20 & No & .560 & .417 & .459 \\
4 & 20 & Yes & .496 & .364 & .436 \\
10 & 10 & No & .519 & .426 & .465 \\
10 & 10 & Yes & .445 & .256 & .423 \\
10 & 20 & No & .426 & .181 & .330 \\
10 & 20 & Yes & .321 & .152 & .302
\end{tabular}

Note: Standard errors of $p^{o b s}$ are all in the range $[.013, .016]$. BNE is indicated by an asterisk and QRE by $\hat{\lambda}$, the maximum likelihood estimate of the degree of error.

An interesting pattern in the data that is clearly seen in Figure 1 is that, relative to BNE we find over-entry for the treatments where $p^{*}<1 / 2$ and (weak) under-entry for the treatments where $p^{*}>1 / 2$. This is not just a coincidence, but is a general property of regular QRE in these games. The independent random noise in QRE flattens out the treatment response in entry rates compared with BNE, by pulling the rates away from BNE in the direction of $p=1 / 2$ (see Goeree and Holt 2005; Goeree, Holt and Palfrey 2016).

\footnotetext{
14 For example, in No Party the empirical BNE entry rate in a treatment is computed by dividing the number of observed ideal points at or more extreme than the two theoretical BNE cutpoints by the total number of observed ideal points. And, the empirical QRE entry rate in a treatment is the average of all theoretical QRE rates per ideal point, weighted by the respective relative frequencies of observed ideal points.
} 
Figure 1: Entry rates - Predictions and data

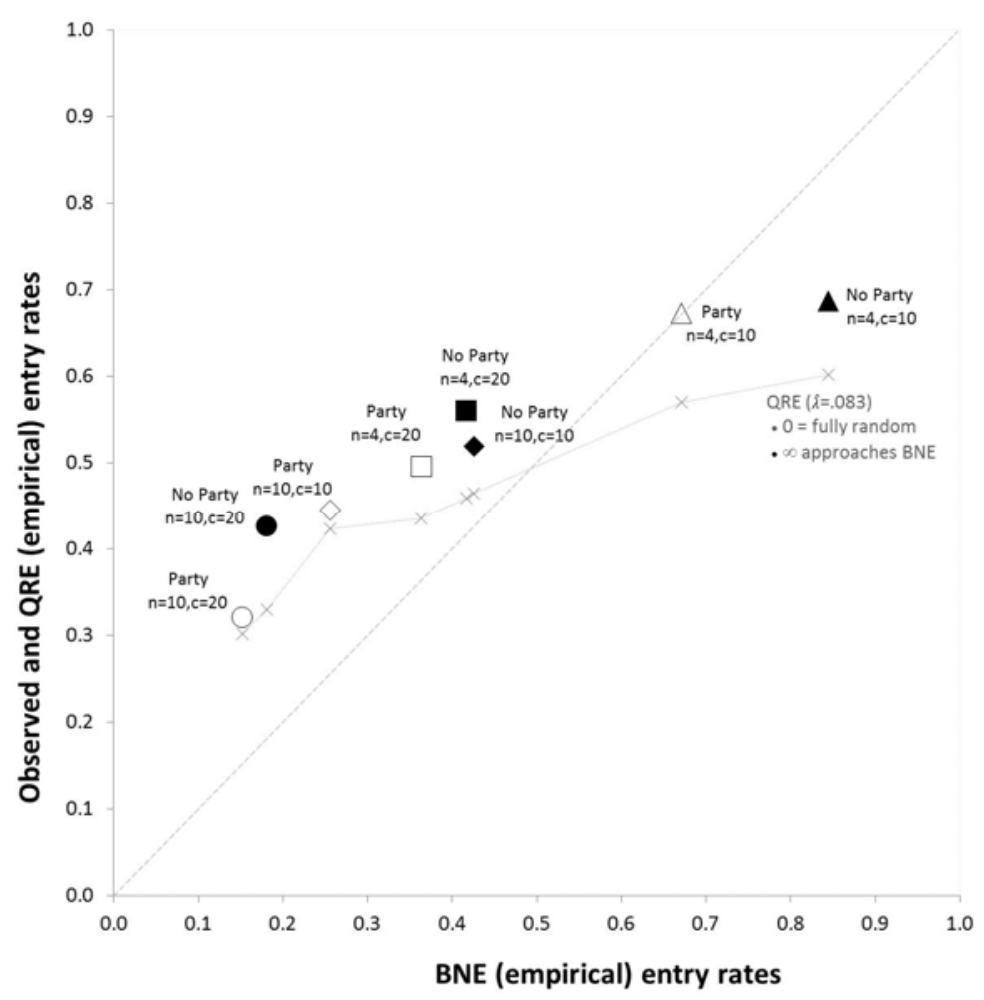

Note: The data markers and empirical $\operatorname{QRE}(\hat{\lambda}=0.083)$ entry rates use all periods.

Figure 2 displays for each treatment the observed and empirical QRE entry rates per block of ten ideal points (solid lines), the BNE cutpoint pair (cross markers at the top), and the theoretical QRE entry rate function (dashed lines) at the estimated value of $\hat{\lambda}^{15}$ With pure noise, $\lambda=0$, the dashed line would be a horizontal through $p=0.5$ and in BNE, $\lambda \approx \infty$, it would be a step function with entry rates equal to one for all ideal points at or more extreme than the two cutpoints (cross markers) and equal to zero for all ideal points strictly within both cutpoints. ${ }^{16}$ (see appendix). Not surprisingly, the sharp BNE cutpoint pairs are not found in the aggregate data. ${ }^{17}$ Instead, in all treatments the entry curves are U-shaped, which is a general property of QRE in these games. ${ }^{18}$

\footnotetext{
15 Figure B1 in Appendix B displays the average entry rates for normalized ideal points, that is, the difference between own ideal point and the closer of the two BNE cutpoints.

${ }^{16}$ Figure A1 in Appendix A displays the QRE entry probabilities for various degrees of error for the No Party, $n=4, c=20$ treatment. These entry probabilities for other treatments vary as expected, but with similar overall shapes.

17 We report an analysis of individual cutpoints in the next section. Behavior in voter turnout experiments is somewhat more similar to BNE cutpoints than in our study (e.g., Levine and Palfrey 2007). More noise in decisions here may arise from more complexity in the citizen candidate game and little feedback about other participants' ideal points (see footnote 10), which hampers learning towards BNE.

${ }_{18}$ Notice the small hills in QRE around the median in Party (lower two panels in Figure 2) where individuals have a stronger incentive to enter than their somewhat more extreme neighbors. For sufficiently low entry costs, this leads to an additional BNE with two cutpoint pairs. The first "outer" pair dictates that all citizens with ideal points at or more extreme than these cutpoints enter, and the second, narrower "inner" pair around the median dictates that all citizens with ideal points at or within this pair enter. The two Party treatments with a low entry cost have such an additional BNE. Note that we observe very similar general entry patterns in all our treatments.
} 
Figure 2: Entry rates per ideal point (data averaged in blocks of ten) - Predictions and data
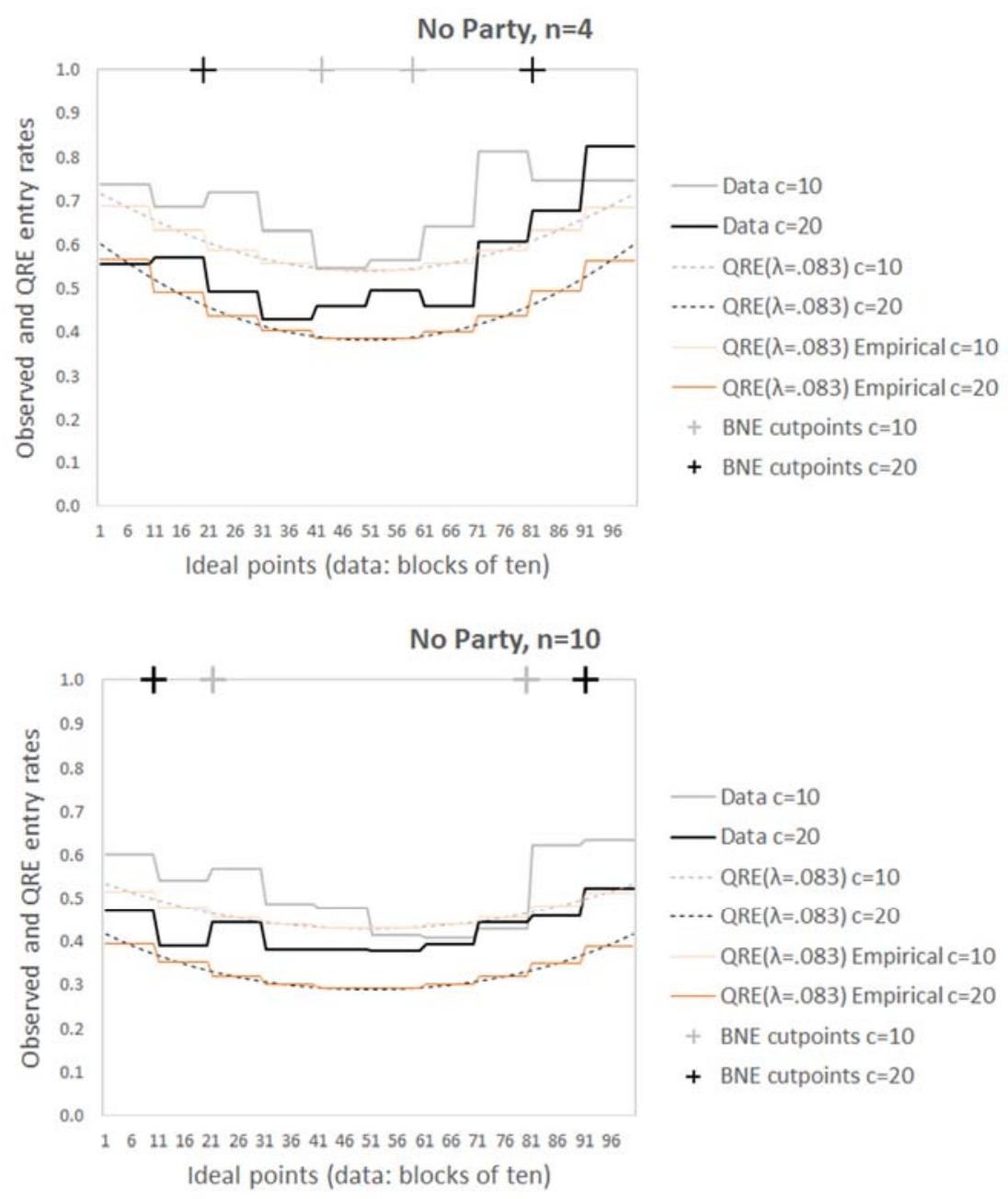

Data C=10

- Data $c=20$

… $\operatorname{QRE}(\lambda=.083) \mathrm{C}=10$

… $\operatorname{QRE}(\lambda=.083) \mathrm{C}=20$

$\operatorname{QRE}(\lambda=.083)$ Empirical $\mathrm{c}=10$

- $\operatorname{QRE}(\lambda=.083)$ Empirical $c=20$

+ BNE cutpoints $\mathrm{c}=10$

+ BNE cutpoints $\mathrm{c}=20$

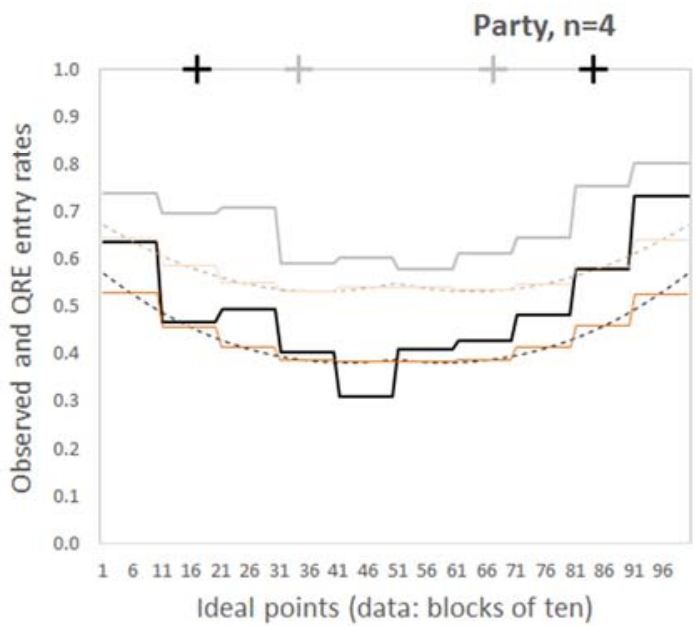

Data $\mathrm{c}=10$

- Data c=20

…. QRE $(\lambda=.083) \mathrm{c}=10$

… QRE $(\lambda=.083) \mathrm{c}=20$

QRE $(\lambda=.083)$ Empirical $c=10$

QRE $(\lambda=.083)$ Empirical $c=20$

+ BNE cutpoints $\mathrm{c}=10$

+ BNE cutpoints $\mathrm{c}=20$ Ideal points (data: blocks of ten) 


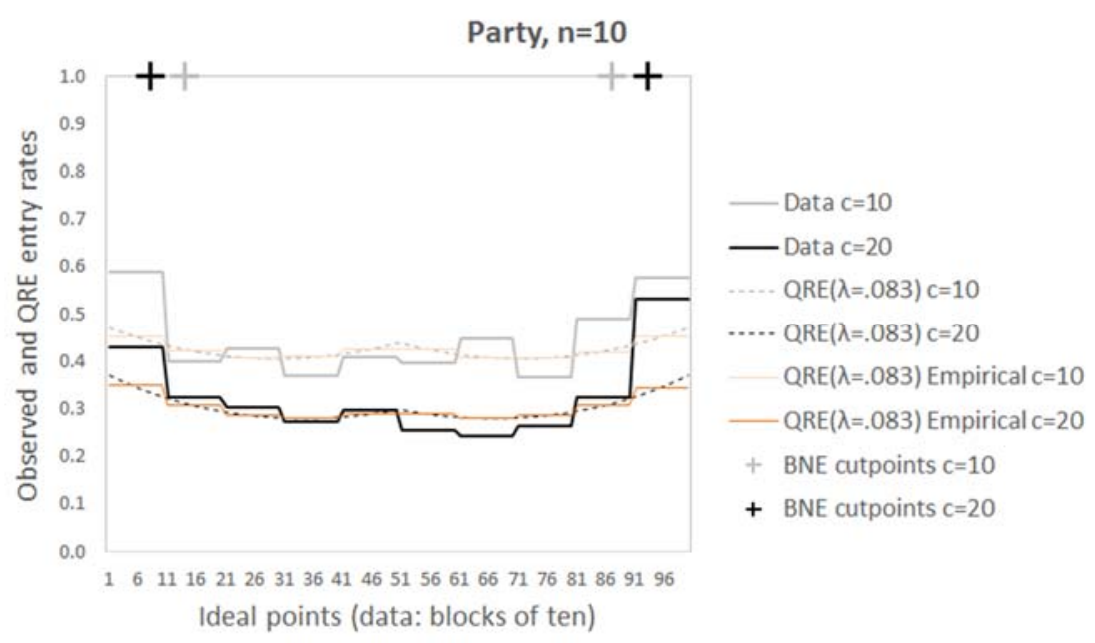

The statistical significance of the U-shape of entry rates is supported by a logit regression (clustered by individuals; see Table 3) of entry decisions on extremeness of a citizen's ideal point, measured by $\left|x_{i, t}-x_{\text {median }}\right| / 49$, where $x_{\text {median }} \in\{50,51\}$ depending on which is closer to $x_{i, t}$ (we chose not the "true" median of 50.5 to normalize the coefficient by dividing by the maximum distance of $49=50-1$ or $100-51$ ). The regression also controls for the three treatment variables and a measure of experience (first fifteen periods versus last fifteen periods in each part). The coefficient of $\left|x_{i, t}-x_{\text {median }}\right| / 49$ is positive and highly significant so the more extreme the own ideal point, the more likley a participant is to run for office. This provides strong support for H1. We next turn to the hypotheses about specific treatment effects.

Table 3: Random-effects logit regression (all data) Dependent dummy variable: Entry decision $\left(1\right.$ if $e_{i, t}=1$ )

\begin{tabular}{|c|c|c|c|c|c|c|}
\hline & \multirow[b]{2}{*}{ Constant } & \multirow[b]{2}{*}{$\frac{\left|x_{i, t}-x_{\text {median }}\right|}{49}$} & \multicolumn{4}{|c|}{ Dummy independent variables } \\
\hline & & & $\begin{array}{l}\text { Entry cost } \\
(1 \text { if } c=20)\end{array}$ & $\begin{array}{l}\text { Group size } \\
(1 \text { if } n=10)\end{array}$ & $\begin{array}{l}\text { Party } \\
\text { (1 if Party) }\end{array}$ & $\begin{array}{l}\text { Block of } 15 \\
\text { periods }\left(1 \text { if } 2^{\text {nd }}\right)\end{array}$ \\
\hline $\begin{array}{l}\text { Coeff. \& Const. } \\
\text { (Std. error) }\end{array}$ & $\begin{array}{l}\mathbf{0 . 6 3 7} \text { *** } \\
(0.211)\end{array}$ & $\begin{array}{l}1.242^{* * *} \\
(0.087)\end{array}$ & $\begin{array}{l}-\mathbf{0 . 7 1 4} * * * \\
(0.051)\end{array}$ & $\begin{array}{l}-\mathbf{1 . 0 5 4} * * * \\
(0.231)\end{array}$ & $\begin{array}{l}-\mathbf{0 . 4 2 5 *} \\
(0.230)\end{array}$ & $\begin{array}{l}\mathbf{- 0 . 0 2 8} \\
(0.050)\end{array}$ \\
\hline
\end{tabular}

Note: * $(* * ; * *)$ indidcates a one-tailed $5 \%(1 \%, 0.1 \%)$ significance level. The data is clustered at the indvidual level.

\subsection{Treatment effects on entry rates and welfare (H2-H5)}

\section{Entry rates (p)}

As clearly seen in Table 2 and Figure 1, all twelve predicted primary treatment effects on entry rates find support in the data. For the party effect (H2), holding constant the group size and entry cost, the observed entry rates are always greater in No Party than Party. For the size effect (H3), holding 
constant the entry cost and party mode, they are always greater with $n=4$ than 10 . And, for the cost effect (H4), holding constant the group size and party mode, they are always greater with $c=10$ than 20 points. The results of the logit regression reported in Table 3 support these treatment effects: the coefficients of Party, Group size, and Entry cost are all negative and statistically significant. While the regression uses all the data, the same results occur when only the respective sessions of primary treatment comparisons are employed, except for the Party dummy with $n=4$ and $c=10$ (the coefficient is insignificant). Overall, our experiment provides strong evidence in favor of $\mathrm{H} 2$ to $\mathrm{H} 4$ with respect to entry decisions. Finally, whether entry decisions are made in the first or second 15 periods in a treatment makes no difference (i.e., the coefficient of Block of 15 periods is insignficant). ${ }^{19}$

\section{Welfare $\left(\pi_{e}\right)$}

We next turn to H5, which addresses the comparative statics predictions of aggregate welfare, as measured by average payoffs. Table 4 gives per treatment observed and predicted (using empirical ideal point distributions) average individual payoffs. Note that all primary qualitative predictions of payoffs are identical for BNE and QRE( $(\hat{\lambda})$, independent of whether they are theoretical or empirical predictions (see appendix). For the welfare effect (H5), all twelve primary qualitative predictions find support in the data. In terms of quantitative comparisons with the equilibrium predictions, in all treatments the actual average payoff $\bar{\pi}^{o b s}$ is greater than in BNE and weakly smaller than in $\operatorname{QRE}(\hat{\lambda})$, but the data and QRE predictions tend to be much closer to one another. ${ }^{20}$

Table 4: Average individual payoffs - Predictions and data

\begin{tabular}{ccr|ccc}
$n$ & $c$ & Party & $\bar{\pi}^{\text {obs }}$ & $\bar{\pi}_{e m p}^{*}$ & $\bar{\pi}_{e m p}^{\hat{\lambda}}$ \\
\hline 4 & 10 & No & 69.26 & 67.00 & 70.67 \\
4 & 10 & Yes & 70.42 & 69.06 & 72.14 \\
4 & 20 & No & 64.22 & 64.00 & 66.95 \\
4 & 20 & Yes & 68.03 & 66.56 & 68.73 \\
10 & 10 & No & 64.44 & 60.28 & 65.01 \\
10 & 10 & Yes & 68.31 & 63.98 & 68.31 \\
10 & 20 & No & 62.61 & 59.25 & 63.24 \\
10 & 20 & Yes & 64.35 & 61.89 & 65.91
\end{tabular}

Note: Standard errors for $\bar{\pi}^{\text {obs }}$ are in the range $[.71, .82]$.

Next, Table 5 gives the results of an OLS regression, clustered by individuals and pooling all data, with the individual payoff in period $t$ as the dependent variable and the same five independent

\footnotetext{
${ }^{19}$ We find no significant learning effects in the data when using other specifications of time.

${ }^{20}$ Recall that the QRE was estimated to fit the choice probabilities of the participants, not by fitting the expected payoffs in the game. Table B3 in Appendix B shows average payoffs, broken down by policy losses, entry expenses, and the spoils of office.Table B4 shows the observed values for leaders and non-leaders, respectively.
} 
variables as in Table 3. As can be seen, all of the predicted effects are highly significant and large in magnitude. And, as in the logit regression for entry rates, there is no evidence of learning.

Table 5: Random-effects OLS regressions (all data)

Dependent variable: Individual period payoff

Dummy independent variables

\begin{tabular}{|c|c|c|c|c|c|c|}
\hline & Constant & $\frac{\left|x_{i . t}-x_{\text {median }}\right|}{49}$ & $\begin{array}{l}\text { Entry cost } \\
(1 \text { if } c=20)\end{array}$ & $\begin{array}{l}\text { Group size } \\
(1 \text { if } n=10)\end{array}$ & $\begin{array}{l}\text { Party } \\
\text { (1 if Party) }\end{array}$ & $\begin{array}{l}\text { Block of } 15 \\
\text { periods }\left(1 \text { if } 2^{\text {nd }}\right)\end{array}$ \\
\hline $\begin{array}{l}\text { Coeff. \& Const. } \\
\text { (Std. error) }\end{array}$ & $\begin{array}{l}\mathbf{7 5 . 4 4}^{* * *} \\
(0.76)\end{array}$ & $\begin{array}{l}-\mathbf{1 4 . 1 4} \\
(0.91)\end{array}$ & $\begin{array}{l}-\mathbf{3 . 2 4}^{* * *} \\
(0.53)\end{array}$ & $\begin{array}{l}-\mathbf{3 . 1 8}^{* * *} \\
(0.54)\end{array}$ & $\begin{array}{l}\mathbf{2 . 5 9} * * * \\
(0.53)\end{array}$ & $\begin{array}{l}\mathbf{- 0 . 0 3} \\
(0.53)\end{array}$ \\
\hline
\end{tabular}

Note: * $\left.{ }^{* *} ;{ }^{* *}\right)$ indicates a one-tailed $5 \%(1 \%, 0.1 \%)$ significance level. The data is clustered at the indvidual level.

The reason for the welfare gains from party-organized elections is that, compared to No Party, majority candidates in Party win more often on average since if there are two nominees, each citizen votes for the one located in the same direction as herself (below we show that participants mostly vote in this way). That is, party labels provide valuable information to all the citizens so the outcome more closely reflects the true distribution of preferences. Figure 3 indicates that for both $n=4$ and 10 (left and right panel, respectively) the majority wins indeed substantially more often in Party than No Party in situations where it might also lose.21 The only exception are majorities of nine participants, which always provided the leader in both party modes.

Figure 3: Actual win proportion and vote coordination advantage of majority parties
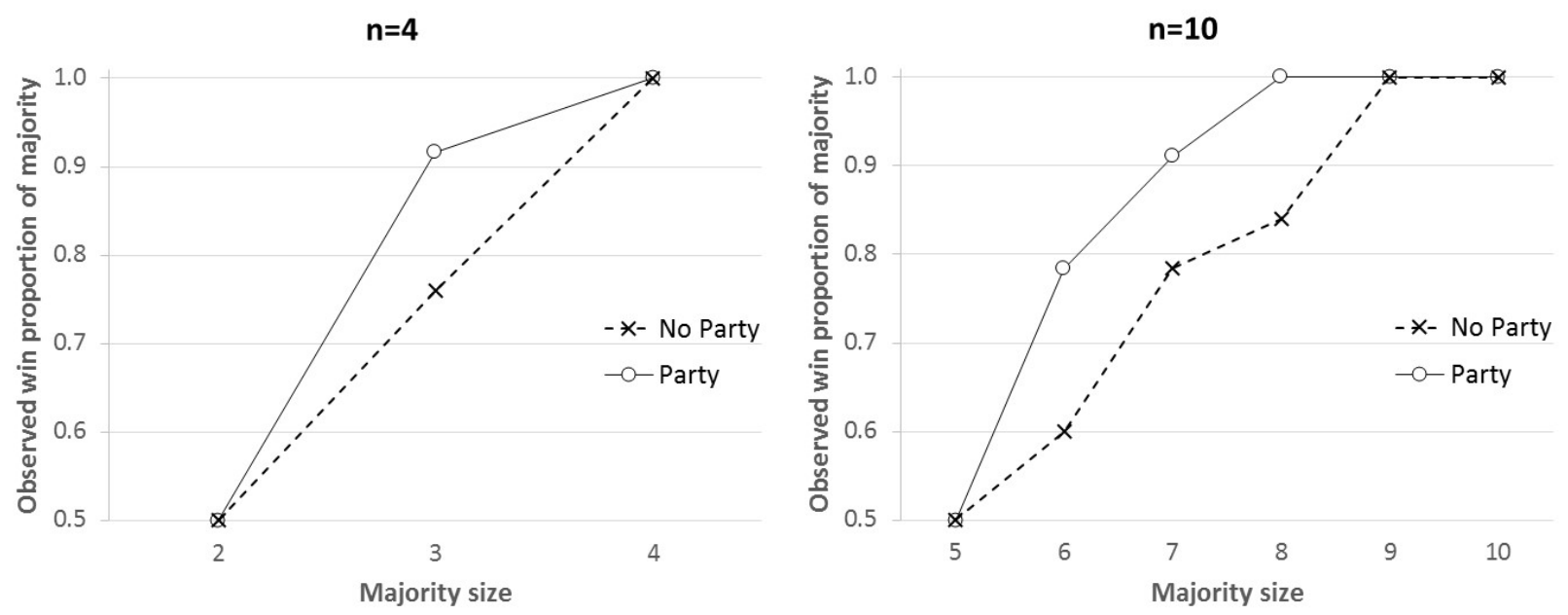

21 Figure B2 in Appendix B displays the frequency distributions of the number of participants per direction. 


\subsection{Complete ordering of entry rates and welfare across treatments (H6 and H7)}

As noted earlier, because BNE produces quantitative predictions about entry and welfare for any parameter configuration, it also generates hypotheses about comparisons across treatments that differ in two or three of the treatment variables. In fact, as stated in $\mathrm{H} 6$ and H7, BNE generates a complete strict order over the eight treatments with respect to both entry rates and welfare.

For entry rates, this is most clearly seen in Figure 2 by the left-right ordering of the labeled data points for each treatment: with only one exception, the data markers are increasing in the BNE entry rate. In fact, out of all 28 possible qualitative comparisons only one has an unpredicted sign, namely $p^{o b s}(4,20$, No Party $)>p^{o b s}(10,10$, No Party $)$, for which the predictions $p_{\text {emp }}^{*}=0.417$ and 0.426 are very close to one another. This provides strong evidence in favor of H6. It is also worth mentioning that while the BNE and $\mathrm{QRE}(\hat{\lambda})$ models generate the same treatment ordering of entry rates, except for (Party, $n=4, c=10$ ) the latter predictions are always nearer to the data. Interestingly, relative to BNE we find over-entry if $p^{*}<0.5$ and (weak) under-entry if $p^{*}>0.5$, a pattern that was already reported in various other binary choice, entry experiments and explained using QRE (Goeree and Holt 2005). As noted before, the logit QRE model also generates this entry pattern. However, it is also the case that the observed entry rates are shifted up relative to the QRE fitted estimates. Finally, the complete order of expected welfare, as measured by average individual payoffs given in Table 4, is also mostly consistent with the BNE and $\mathrm{QRE}(\hat{\lambda})$ predictions (note that the two models predict somewhat different orders). Out of 28 possible qualitative comparisons, 24 and 25 are correct, respectively. This includes all twelve of the one-variable treatment comparisons discussed in the last section, and twelve and thirteen out of sixteen of the comparisons between treatments that differed in more than one dimension. Thus, the data provide some support for H7, but weaker than the solid support that we find for H6.

\section{Experimental results: Individual behavior}

\subsection{Voting behavior}

The predicted voting behavior in BNE is quite simple: (1) each candidate in No Party and each nominee in Party votes for herself; (2) with two nominees each non-nominee votes for the one whose ideal point is from her own subset of ideal points, left or right. We label voting decisions that are inconsistent with these predictions as unexpected. ${ }^{22}$ Table 6 shows the observed average individual rate of unexpected voting for each treatment. The rate of each participant is equally weighted and

22 Of course, unexpected votes never occur for non-candidates in No Party (who are predicted to vote randomly) nor for elections with zero or one entrant, so these situations are excluded from the analysis. 
computed by dividing her number of unexpected votes by the number of cases she or he is a candidate respectively nominee or non-nominee. As can be seen, candidates and nominees do indeed mostly vote for themselves. Specifically, in No Party (Party) unexpected votes by candidates or nominees are observed only 0.8 to 4.2 ( 0 to 3.5 ) percent of the time. Similarly, non-nominees in Party rarely cast unexpected votes (only 2.0 to 6.5 percent of the time). Thus, overall voting behavior is very close to BNE.

Table 6: Observed unexpected votes

\begin{tabular}{|c|c|c|c|c|}
\hline \multirow[b]{2}{*}{$n$} & \multirow[b]{2}{*}{ c } & \multirow[b]{2}{*}{ Party } & \multicolumn{2}{|c|}{$\begin{array}{l}\text { Average individual rates of } \\
\text { unexpected votes (std. errors) }\end{array}$} \\
\hline & & & $\begin{array}{l}\text { Candidates/ } \\
\text { Nominees }\end{array}$ & Non-nominees \\
\hline 4 & 10 & No & $.042(.017)$ & - \\
\hline 4 & 20 & No & $.026(.015)$ & - \\
\hline 10 & 10 & No & $.025(.014)$ & - \\
\hline 10 & 20 & No & $.008(.004)$ & - \\
\hline 4 & 10 & Yes & $.035(.025)$ & $.052(.020)$ \\
\hline 4 & 20 & Yes & $.007(.007)$ & $.020(.011)$ \\
\hline 10 & 10 & Yes & $.000(.000)$ & $.057(.018)$ \\
\hline 10 & 20 & Yes & $.000(.000)$ & $.065(.021)$ \\
\hline
\end{tabular}

Note: Elections with zero or one entrant are excluded. Non-nominee's rates are for the Party treatments only. Standard errors are computed using the differences in each individual's rate and the average individual rate.

Figure 5 displays the distribution of the number of unexpected votes across all participants, with the number of such votes on the horizontal axis (from zero to the maximum observed of eighteen) and the respective fraction of individuals on the vertical axis. The figure also separates out the observations for independent candidates, nominees, and non-nominees as they face different decision tasks. ${ }^{23}$ The diagonal axis shows combinations of party mode and group size, with data pooled for both entry costs. The figure indicates that only very few participants voted unexpectedly. Specifically, 77.8 and 82.5 percent of the independent candidates in 4- and 10-person groups always voted as predicted, and these numbers are 87.5 and 100 percent for nominees and 71.9 and 57.5 percent for non-nominees, respectively. And of the participants who cast at least one anomalous vote, many did so just once or little more than this. Hence, the few deviations from equilibrium voting are due to the behavior of only a handful of the participants in the experiment. For example, the three largest individual counts of unexpected votes are seventeen by a candidate in (No Party, $n=4)$ and

\footnotetext{
${ }^{23}$ Compared to nominees in Party, there can be more than two contenders to choose from by candidates in No Party, including themselves. And, non-nominees in Party must realize that their expected payoff is greater if they vote for the contender whose ideal point is from the same direction as the own one, while nominees simply vote for themselves.
} 
thirteen and eighteen by two non-nominees in (Party, $n=10$ ), where the latter of them never entered.

Figure 5: Number of unexpected votes per individual

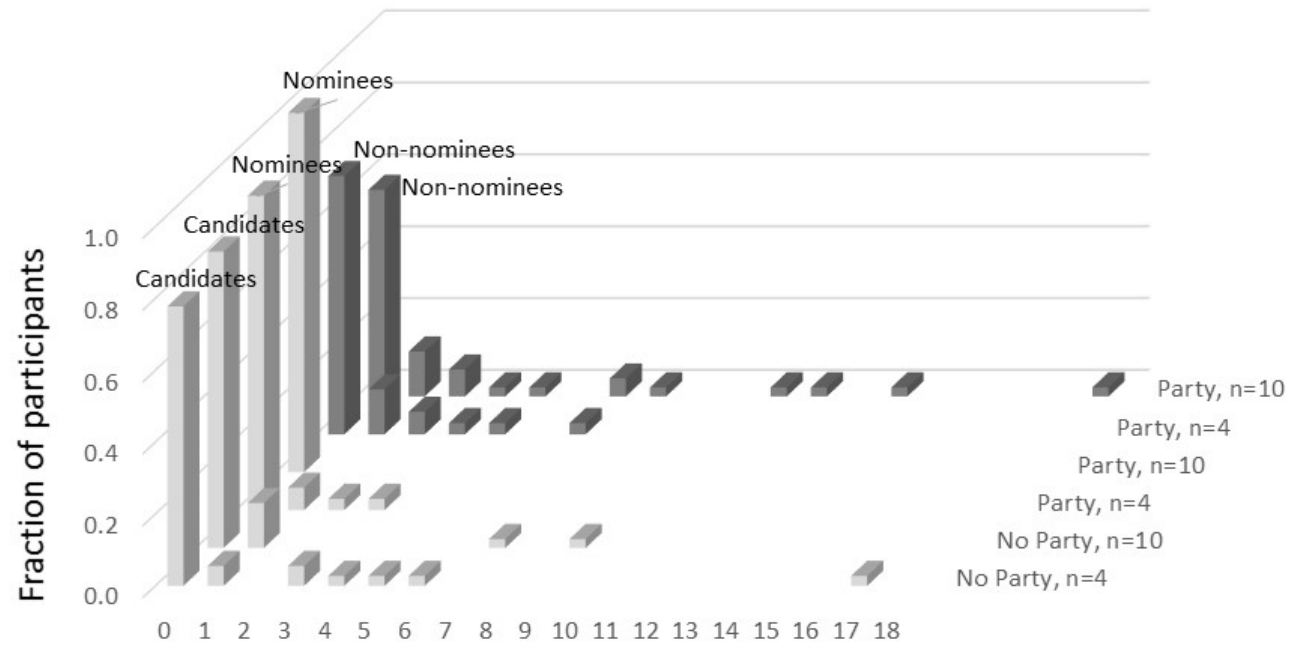

Number of unexpected votes per participant

Note: The fractions are shown per independent candidates, nominees, and non-nominees and are pooled for both entry cost treatments, so the figure connects only the party mode and group size.

Next, we analyze whether the observed rates of unexpected voting depend on the ideal point. ${ }^{24}$ Figure 6 shows the rates on the vertical axis and the absolute distance in the own ideal point and the closer "median" ideal point, 50 or 51, on the horizontal axis. Thus, at zero on the horizontal axis both ideal points coincide and at 49 the distance between them is maximal. The figure shows the data (lines with spikes) and respective logarithmic trend lines for candidates and nominees combined and for non-nominees (thick black and gray lines, respectively), and also separate logarithmic trends for candidates and nominees (dashed black lines) and non-nominees who did and did not enter (dashed gray lines). As can be seen, unexpected voting of candidates and nominees doesn't depend on the own ideal point (Spearman's $\rho=-0.018$ for both roles combined and -0.037 and 0.034 for each role, respectively; $p \geq 0.799$ ) and is higher for candidates (but the difference is insignificant, $p=0.115$, individual level one-tailed Wilcoxon-Mann-Whitney test, fifteen and four participants per role).

24 The following analysis pools all data and utilizes only participants who cast at least one unexpected vote in the entire session. Using instead all participants in the nonparametric tests yields many ties and decreases the $p$-values, except for two increases where the results are statistically significant whether or not all individuals are considered. 
Figure 6: Unexpected voting per absolute distance in own and median ideal points

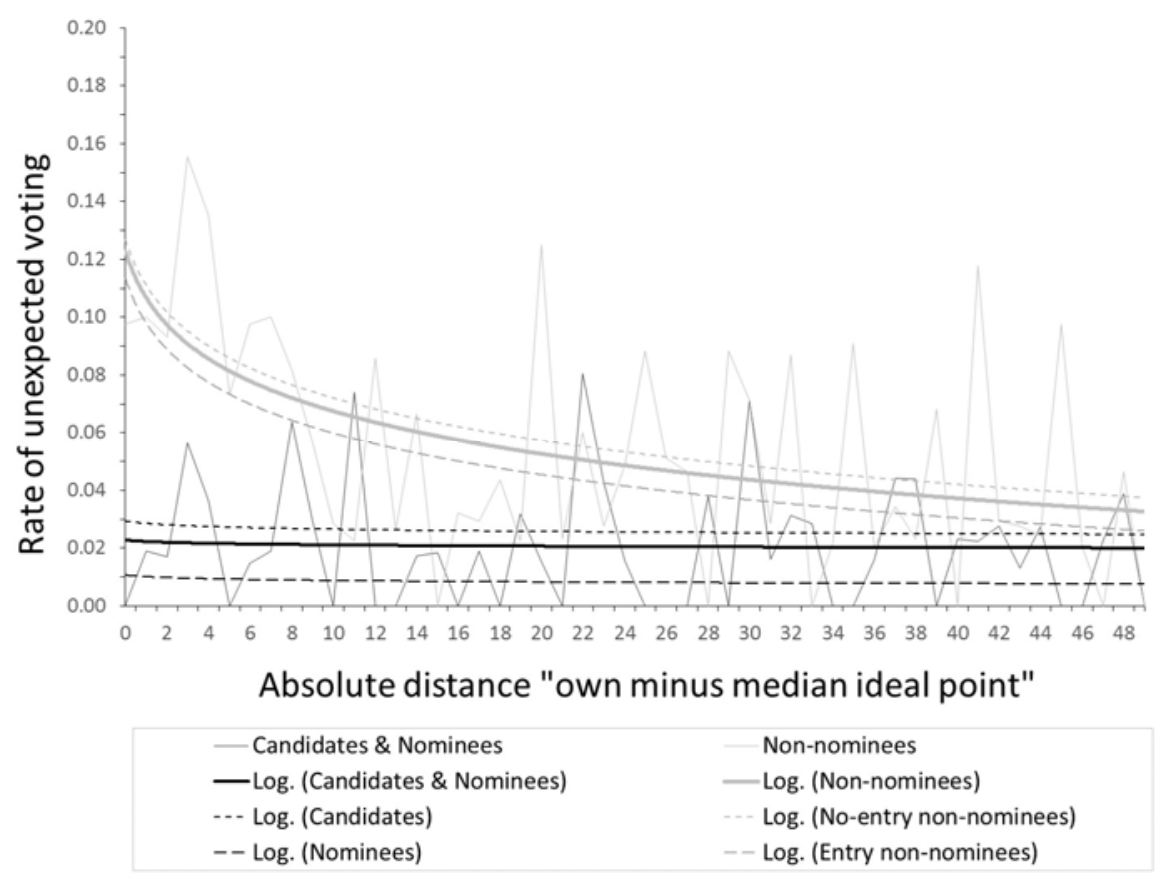

Note: The figure depicts unexpected voting rates per absolute distance in own and median ideal points for nonnominees and for candidates and nominees combined. At zero, the own ideal point is 50 or 51 , and at 49 (50 1 or $100-51$ ) the distance is maximal. The dashed lines show the respective logarithmic trends.

By contrast, we observe a negative association between unexpected voting and the absolute distance in the own and median ideal points for non-nominees $(\rho=-0.424$ overall, and -0.363 and -0.352 for entrants and non-entrants; $p \leq 0.012$ ). In Party, note that anomalous voting of nonnominees tends to be smaller when they entered $(p=0.006$, one-tailed Wilcoxon signed-ranks test, 25 individuals) and especially high for ideal points within about ten points of the median. Also, the rates are always greater in the non-nominee than nominee role $(p=0.003$, same test, 26 individuals). Overall, our results indicate that among those who vote unexpectedly, candidates and nominees make "plain" errors while for non-nominees models that incorporate the pecuniary consequences of erroneous voting and beliefs about nominee ideal points seem more suitable. ${ }^{25}$ This also makes sense, since the expected payoff-maximizing vote is more obvious for candidates and nominees than for non-nominees, ${ }^{26}$ which is also supported by learning towards BNE voting of

25 For example, QRE (McKelvey and Palfrey 1995, 1998) allows for decision-making errors and thus unexpected voting. It also predicts that such votes get more frequent the nearer an ideal point is to 50 or 51, as the expected policy loss if someone else is elected decreases towards the median.

26 Table 6 suggests two more patterns of average individual rates of unexpected voting for primary comparisons. First, the rates are always weakly greater with a lower than larger entry cost for candidates and nominees $(p=0.035$, one-tailed Wilcoxon signed-ranks test for both roles combined, eighteen individuals), but no pattern is seen for non-nominees (albeit, $p=0.074$ in favor of greater rates with a lower cost, same test, 26 individuals). Second, the rates are always greater in smaller than larger groups for candidates and nominees $(p=0.029$, one-tailed Wilcoxon-Mann-Whitney test, twelve and seven individuals in 4- and 10-person groups, respectively), and the reverse is seen for non-nominees (but the difference 
participants in the latter role: while unexpected voting doesn't depend on the period for candidates and nominees combined using all 60 periods or the first and last 30 periods only (Spearman's $\rho=$ $-0.112,-0.247$, and $-0.029 ; p \geq 0.188$ ), it does so negatively for non-nominees for all 60 and last 30 periods ( $\rho=-0.312$ and $-0.378 ; p=0.093$ and 0.003 , respectively) but not the first 30 periods $(\rho=-0.159, p=0.402)$.

\subsection{Individual entry behavior}

Here we present individual level data of entry behavior. Figure 7 depicts cumulative frequency distributions of actual average individual entry rates for (No Party, $c=10, n=4$ ) and (Party, $c=20, n=10)$, which have with $p_{e m p}^{*}=0.844$ and 0.152 the most extreme BNE entry

Figure 7: Cumulative distribution of individual entry rates (for lowest and highest BNE entry)

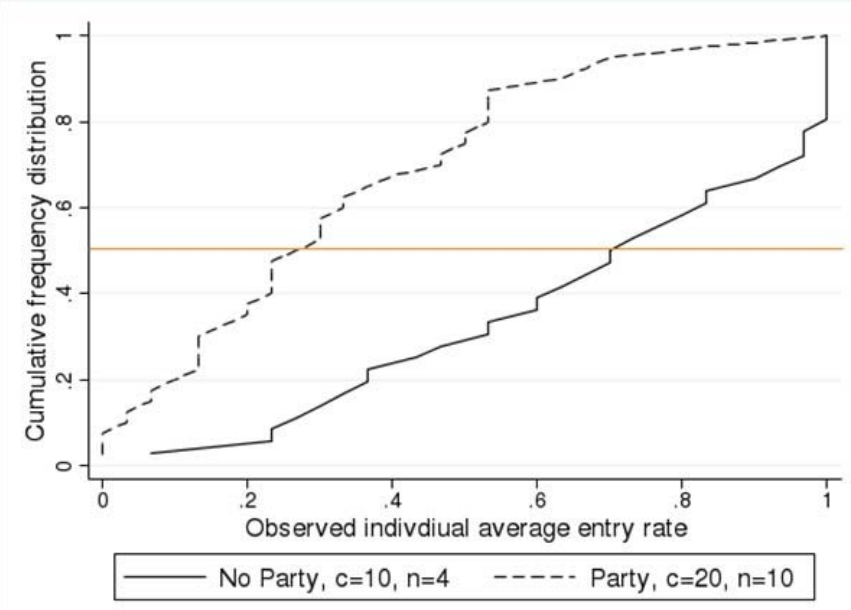

probabilities. The distributions of the six other treatments tend to fall within these two distributions. ${ }^{27}$ Clearly, there is marked heterogeneity in entry rates among participants. Further, the 50 percent horizontal line intersects the two distributions in the expected order, but more to the left and right relative to $p_{e m p}^{*}=0.844$ and 0.152 , respectively. This is consistent with QRE, which pulls the entry rates away from BNE towards $1 / 2$.

The scatter plot in Figure 8 shows, for each participant, the average entry rate with $c=10$ and 20 points on the horizontal and vertical axis, respectively. Each marker represents one

is not significant, $p=0.241$, same test, nine and seventeen individuals). Finally, for the two possible within-subject comparisons, unexpected voting is neither associated between both entry costs for candidates and nominees combined and for non-nominees nor between the nominee and non-nominee roles in Party (Spearman's $\rho=-0.026,0.105$, and 0.058; $p \geq 0.611$ ). Due to few unexpected votes by few individuals, all these findings are hard to interpret as we would need to control for, say, ideal points and expected payoffs.

27 See Figure B3 in Appendix B. The cumulative distributions of entry rates of (No Party, $c=10, n=4)$ and $($ Party, $c=$ $10, n=4$ ) intersect once. 
individual, where different symbols indicate different combinations of the party mode and group size (a few markers are somewhat magnified in proportion to the number of individuals at that same coordinate). As expected, independent of party mode and group size, most individuals enter more often when it costs less (i.e., have markers below the diagonal; one-tailed Wilcoxon signed ranks tests, $p<0.001$ for each party mode and group size combination). Specifically, only 28 out of all 148 participants entered more often with a larger cost, and most of them are found close to the diagonal. Also, fourteen participants have the same entry rates with both costs (i.e., with markers on the diagonal), of whom one never entered and six always entered.

Figure 8: Entry cost effect

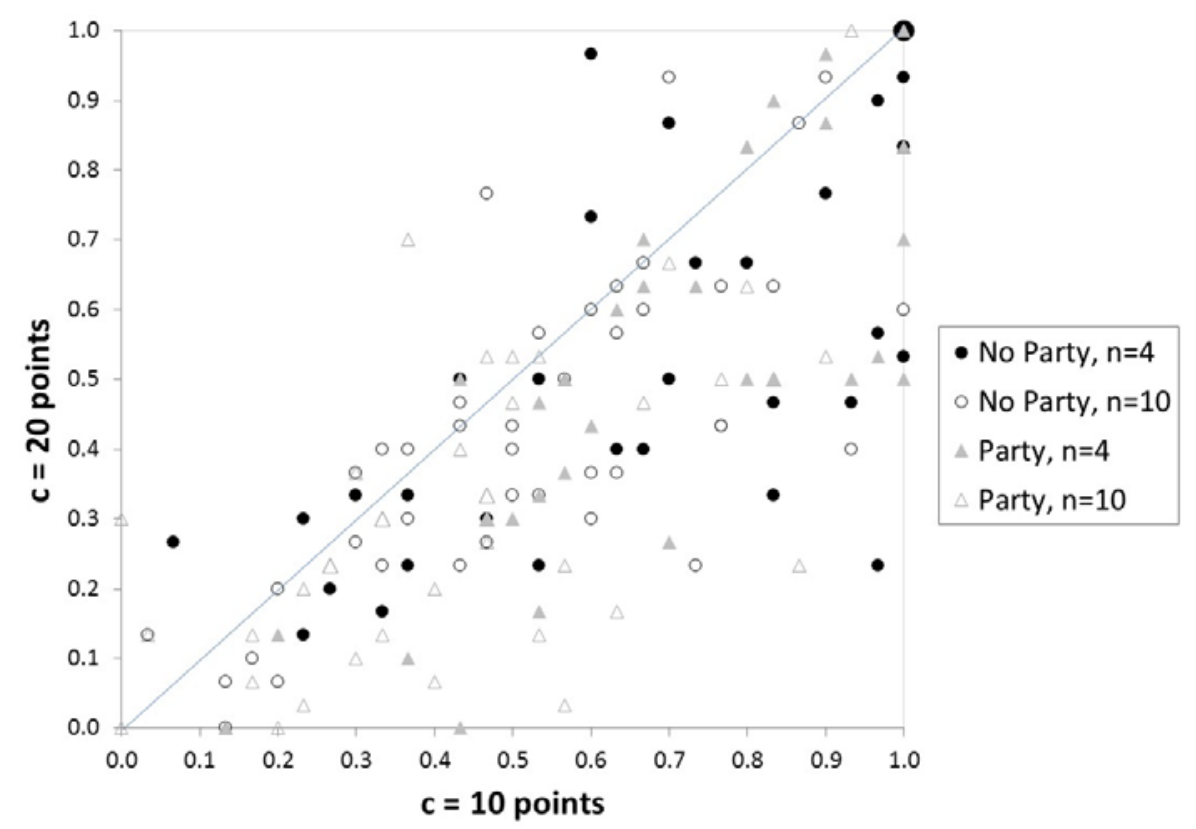

Note: Each participant's average entry rate with $c=10$ and 20 points is shown on the horizontal and vertical axis, respectively. Each marker represents one participant, where a few markers are somewhat magnified in proportion to the number of individuals at that coordinate.

Next, we explore the extent to which observed entry decisions are consistent with cutpoint strategies, which are generally optimal best responses in this game. Specifically, for each participant $i$ and treatment $h$ we estimate a cutpoint pair as follows, assuming that individuals use such a decision rule. For each participant and treatment, we have $t=30$ periods or observational pairs of an ideal point and entry decision, $\left(x_{i, t}, e_{i, t}\right)_{h}$. Fixing a cutpoint pair $\left(\check{x}_{l}, \breve{x}_{r}\right)_{i, h}$, with $1 \leq \check{x}_{l} \leq 50$ and $\breve{x}_{r}=101-\check{x}_{l}$ due to symmetry, observation $t$ in treatment $h$ is marked consistent with this cutpoint pair if 


$$
\begin{aligned}
& \text { (i) } \check{x}_{l, i}<x_{i, t}<\check{x}_{r, i} \text { and } e_{i, t}=0 \text {, or } \\
& \text { (ii) } x_{i, t} \leq \check{x}_{l, i} \vee \check{x}_{r, i} \leq x_{i, t} \text { and } e_{i, t}=1,
\end{aligned}
$$

and marked as error otherwise. ${ }^{28}$ And, as an estimator of participant $i$ 's cutpoint pair we choose the one that minimizes the total number of errors, and if there are more such pairs we take the average of them. Using this procedure, we compute the distribution of individual classification error rates and cumulative frequency distributions of estimated individual cutpoint pairs.

Figure 9: Distribution of classification error rates

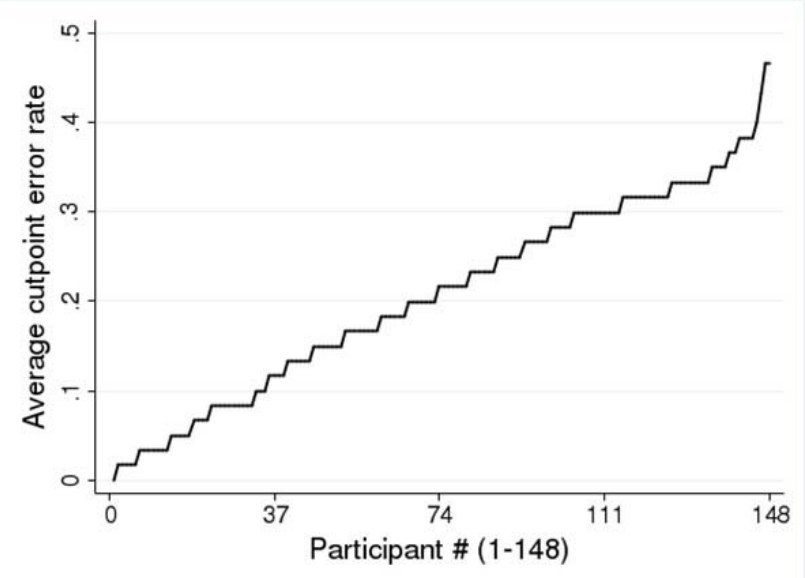

Note: Individual error rates are pooled for both entry costs.

Figure 9 depicts the overall distribution of individual error rates, which are pooled for both entry costs. For about $25(50 ; 75)$ percent of the participants the error rate is $\leq 0.1(0.2 ; 0.3)$, and only three percent have error rates of 0.4 or higher but none reaches the 0.5 . Figure 10 shows the cumulative distributions of estimated individual cutpoint pairs for (No Party, $c=10, n=4)$ and (Party, $c=20, n=10$ ), which have the most moderate and most extreme BNE cutpoint pairs of $[42,59]$ and $[8,93]$, respectively. Due to symmetry we only show the left cutpoints, superimposing the data from both directions. ${ }^{29}$ There is marked heterogeneity among the estimated individual cutpoint pairs. Finally, the 50 percent horizontal line and two distributions intersect in the expected order, and close to the eight and somewhat closer to the median than the 42 predicted, respectively.

\footnotetext{
${ }^{28}$ A citizen's discrete ideal point matches a cutpoint with strictly positive probability and, for our parameters, in equilibrium she can raise her expected payoff by entering. By contrast, Großer and Palfrey (2014) use continuous types so a citizen located at a cutpoint, which almost surely never occurs, is indifferent between entering and not entering and assumed to enter.

${ }^{29}$ The distributions of the other six treatments fall within these two distributions. See Figure 4B in Appendix B.
} 
Figure 10: Cumulative distributions of individual cutpoint pairs (for lowest and highest BNE entry)

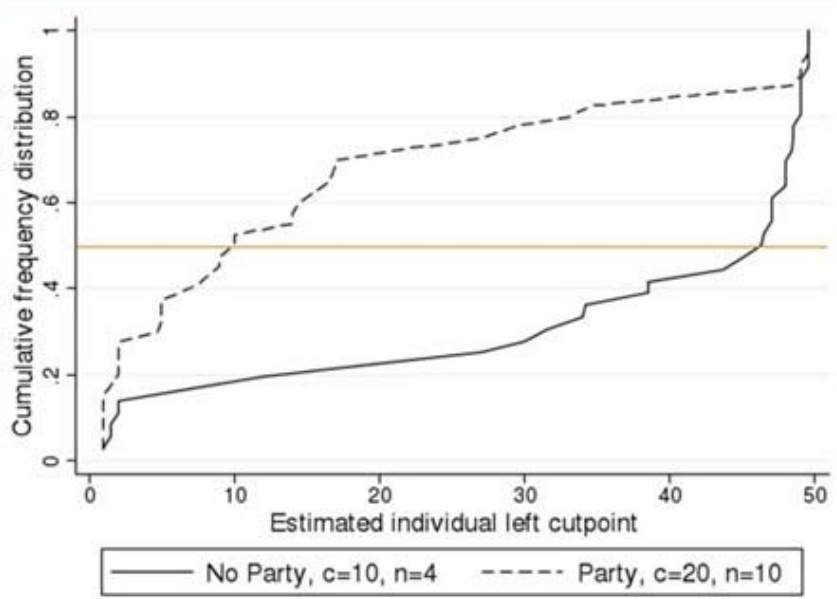

Note: Due to symmetry, we only present the left cutpoints, superimposing the data from both directions.

Table 7 gives the fraction of average individual positive differences in the estimated "left cutpoint with $c=10$ points minus left cutpoint with $c=20$ points." The fraction ranges from 0.58 to 0.78, compared to 1 in BNE, and average differences range from 4.27 to 8.64 (in brackets).

Table 7: Fraction (average) of positive individual cutpoint differences

\begin{tabular}{ccr} 
& Left cutpoint $c=10-$ left cutpoint $c=20$ \\
\cline { 2 - 3 } & No Party & Party \\
\hline$n=4$ & $0.61(8.64)$ & $0.60(6.66)$ \\
$n=10$ & $0.78(8.77)$ & $0.58(4.27)$
\end{tabular}

Note: Party with $n=10$ has two individuals with zero difference, and each of the other three combinations of the party mode and group size has one individual with zero difference.

Overall, participants do not follow sharp cutpoint strategies. While this is inconsistent with optimizing behavior and with BNE, it is very much in line with the behavioral theory behind regular QRE. Participants in this experiment do not always optimize, but generally choose better entry actions more often than worse ones. This is also very much in line with results from cutpoint analysis in binary choice turnout games (Levine and Palfrey 2007), where the vote/abstain choice is similar in nature to enter/not enter.

\section{Conclusions}

This paper reports a laboratory study of a citizen-candidate entry game with incomplete information about the ideal points of citizens and candidates. Ideal points are privately observed iid random draws from a uniform distribution over the set of feasible common policies. Without ideological political parties, citizens have no extra information about the ideal points of independent candidates at the time of voting. By contrast, with parties they learn whether a party nominee's ideal point belongs to the left or right half of the common policy set, but not her exact ideal point. The study 
compares both party modes in 4- or 10-person groups and with two different entry costs. In the entry game, symmetric BNE makes sharp and mostly unique predictions of cutpoint pairs. That is, in equilibrium each citizen with an ideal point at or more extreme than a left or right cutpoint runs for office, while everyone with an ideal point strictly in between the two cutpoints doesn't run. Thus, the model predicts political polarization in the sense that the ideal points of politicians are more extreme than those in the general polity. Finally, the clear distributional BNE entry predictions, from which we also derive implications about welfare, have the advantage of being straightforward to test in the laboratory.

The main experimental results can be summarized as follows. First, all primary comparative statics predictions of entry rates and economic welfare are supported by the data. Most importantly, inefficient political polarization arises in all treatments. Second, participants appear to follow cutpoint strategies with some error, and the distribution of estimated cutpoints indicate significant heterogeneity. Consequently, instead of step functions, actual entry rates are U-shaped functions of the ideal points in all treatments, with over-entry when the BNE entry probability is smaller than 50 percent and (weak) under-entry when it is greater than 50 percent. Because participants with moderate ideal points sometimes enter and win, we observe less political polarization and thus on average a smaller total policy loss and greater economic welfare than predicted (with over-entry, the greater total expense is exceeded by the smaller policy loss). The primary comparative static predictions of logit QRE are all supported in the data, as they are the same as those of BNE, but in addition QRE tracks the levels and patterns of entry and welfare much better. Third, ideological parties lead to more polarization, but at the same time alleviate some of the inefficiencies caused by extreme policies because knowledge of a nominee's party affiliation enables implicit vote coordination in favor of the majority, which is more likely to win than in the absence of parties.

Overall, this study shows empirically that incomplete information in elections can indeed lead to inefficient political polarization through the informational effects on entry. In order to check the robustness of our findings, future research could for example examine various different distributions of ideal points (e.g., asymmetric distributions) and default policies. Another interesting direction is to compare different voting systems (e.g., Bol, Dellis, and Oak, forthcoming) and to study more explicitly the formation of parties and how they select their nominees, such as via primaries (e.g., Hansen 2014). We hope that these findings may inspire further theoretical and empirical work to shed more light on the non-trivial, realistic political processes such as those explored in citizencandidate entry games. 


\section{References}

Ansolabehere, Stephen, Jonathan Rodden, and James M. Snyder Jr. 2008. "The strength of issues: Using multiple measures to gauge preference stability, ideological constraint, and issue voting." American Political Science Review 102 (2): 215-32.

Bafumi, Joseph, and Michael C. Herron. 2010. "Leapfrog representation and extremism: A study of American voters and their Members of Congress." American Political Science Review 104 (3): 51942.

Besley, Timothy, and Stephan Coate. 1997. "An economic model of representative democracy." Quarterly Journal of Economics 112 (1): 85-114.

Bol, Damien, Arnaud Dellis, and Mandar Oak. "Comparison of voting procedures using models of electoral competition with endogenous candidacy." In The political economy of social choice, eds. M. Gallego and N. Schofield. Heidelberg: Springer, forthcoming.

Bol, Damien, Arnaud Dellis, and Mandar Oak. 2015. "Endogenous candidacy in electoral competition: A survey on the number of candidates and their polarization." Working paper.

Cadigan, John. 2005. “The citizen candidate model: An experimental analysis.” Public Choice 123 (12): 197-216.

Camerer, Colin, and Dan Lovallo. 1999. "Overconfidence and excess entry: An experimental approach." American Economic Review 89 (1): 306-18.

Campbell, Angus, Philip E. Converse, Warren E. Miller, and Donald E. Strokes. 1960. The American voter. New York: Wiley.

DiMaggio, Paul, John Evans, and Bethany Bryson. 1996. “Have Americans' social attitudes become more polarized?" American Journal of Sociology 102 (3): 690-735.

Downs, Anthony. 1957. An economic theory of democracy. New York: Harper and Row.

Elbittar, Alexander, and Andrei Gomberg. 2009. "An experimental study of the citizen-candidate model." In The Political Economy of Democracy, eds. E. Aragonés, C. Beviá, H. Llavador, and N. Schofield. Bilbao, Spain: Fundación BBVA, 31-46.

Feddersen, Timothy J. 1992. “A voting model implying Duverger's law and positive turnout." American Journal of Political Science 36 (4): 938-62. 
Feddersen, Timothy J., Itai Sened, and Stephen G. Wright. 1990. "Rational voting and candidate entry under plurality rule." American Journal of Political Science 34 (4): 1005-16.

Fiorina, Morris P., Samuel J. Abrams, and Jeremy C. Pope. 2006. Culture war? The Myth of a polarized America. $2^{\text {nd }}$ ed. New York: Pearson Longman.

Fischbacher, Urs, and Christian Thöni. 2008. "Excess entry in an experimental winner-take-all market." Journal of Economic Behavior \& Organization 67 (1): 150-63.

Goeree, Jacob K. and Charles A. Holt. 2005. "An explanation of anomalous behavior in models of political participation." American Political Science Review 99 (2): 201-13.

Goeree, Jacob K., Charles A. Holt, and Thomas R. Palfrey. 2005. "Regular quantal response equilibrium." Experimental Economics 8 (4): 347-67.

Goeree, Jacob K., Charles A. Holt, and Thomas R. Palfrey. 2016. Quantal response equilibrium: A stochastic theory of games. Princeton University Press.

Goeree, Jacob K. and Jens Großer. 2007. “Welfare reducing polls.” Economic Theory 31 (1): 51-68.

Greiner, Ben. 2015. "Subject pool recruitment procedures: Organizing experiments with ORSEE." Journal of the Economic Science Association. 1 (1): 114-25.

Großer, Jens, and Thomas R. Palfrey. 2009. "A citizen candidate model with private information." In The Political Economy of Democracy, ed. E. Aragonés, C. Beviá, H. Llavador, and N. Schofield. Bilbao, Spain: Fundación BBVA: 15-29.

Großer, Jens, and Thomas R. Palfrey. 2014. “Candidate entry and political polarization: An antimedian voter theorem." American Journal of Political Science 58 (1): 127-43.

Hamlin, Alan, and Michael Hjortlund. 2000. "Proportional representation with citizen candidates." Public Choice 1033 (3-4): 205-30.

Hansen, Emanuel. 2014. "Political competition with endogenous party formation and citizen activists." University of Cologne. Working paper.

Hotelling, Harold. 1929. “Stability in competition.” Economic Journal 39 (153): 41-57.

Kamm, Aaron. 2016. "Plurality voting versus proportional representation in the citizen-candidate model: An Experiment." University of Amsterdam. Working paper.

Levine, David K., and Thomas R. Palfrey. 2007. "The paradox of voter participation? A laboratory study." American Political Science Review 101 (1): 143-58. 
McCarty, Nolan, Keith T. Poole, and Howard Rosenthal. 2006. Polarized America: The dance of ideology and unequal riches. Cambridge, MA: MIT Press.

McKelvey, Richard D., and Thomas R. Palfrey. 1995. "Quantal response equilibrium for normal form games." Games and Economic Behavior 10: 6-38.

McKelvey, Richard D., and Thomas R. Palfrey. 1998. "Quantal response equilibrium for extensive for games." Experimental Economics 1: 9-41.

Osborne, Martin J., and Al Slivinski. 1996. "A model of political competition with citizen candidates." Quarterly Journal of Economics 111 (1): 65-96.

Palfrey, Thomas R. 1984. "Spatial equilibrium with entry.” Review of Economic Studies 51 (1): 139-56.

Palfrey, Thomas R. and Keith T. Poole. 1987. "The relationship between information, ideology, and voting behavior." American Journal of Political Science 31 (3): 511-30.

Palfrey, Thomas R. “A mathematical proof of Duverger's law.” 1989. In Models of strategic choice in politics, ed. P. C. Ordeshook. Ann Arbor: University of Michigan Press: 69-91.

Snyder, James M. Jr., and Michael M. Ting. 2002. "An informational rationale for political parties." American Journal of Political Science 46 (1): 90-110.

Wittman, Donald. 1983. "Candidate motivation: A synthesis of alternative theories." American Political Science Review 77: 142-57. 


\section{Appendix A: Theoretical Derivations}

\section{Best response entry strategies}

Consider our citizen-candidate entry game without parties and with a discrete, uniform cumulative probability function of ideal points $F(x)=x / 100, x \in\{1,2, \ldots, 100\}$ and density $f(x)=1 / 100$. If all citizens $j \neq i$ are using cutpoint strategy (cf. (2) in the main text)

$$
\check{e}_{j}=\left\{\begin{array}{lll}
0 & \text { if } & x_{j} \in\left\{\check{x}_{l}+1, \ldots, \check{x}_{r}-1\right\} \\
1 \quad \text { if } & x_{j} \in\left\{1, \ldots, \check{x}_{l}\right\} \cup\left\{\check{x}_{r}, \ldots, 100\right\},
\end{array}\right.
$$

then the expected payoff of a citizen type $x_{i}$ for entering the political competition, $\check{e}_{i}=1$, is given by

$$
\begin{aligned}
E\left[\pi_{i} \mid x_{i}, \check{e}_{i}=1\right] & =(1-p)^{n-1} b \\
& +\sum_{m=2}^{n}\left(\begin{array}{c}
n-1 \\
m-1
\end{array}\right) p^{m-1}(1-p)^{n-m}\left[\frac{b}{m}-\frac{m-1}{m} E\left[v\left(x_{i}, \gamma\right) \mid \gamma \notin\left\{\check{x}_{l}+1, \ldots, \check{x}_{r}-1\right\}\right]\right]-c
\end{aligned}
$$

and her expected payoff from not entering, $\check{e}_{i}=0$, by

$$
\begin{aligned}
E\left[\pi_{i} \mid x_{i}, \check{e}_{i}=0\right] & =(1-p)^{n-1}\left[\frac{b}{n}-\frac{n-1}{n} E\left[v\left(x_{i}, d\right) \mid d \in\left\{\check{x}_{l}+1, \ldots, \check{x}_{r}-1\right\}\right]\right] \\
& -\sum_{m=2}^{n}\left(\begin{array}{c}
n-1 \\
m-1
\end{array}\right) p^{m-1}(1-p)^{n-m} E\left[v\left(x_{i}, \gamma\right) \mid \gamma \notin\left\{\check{x}_{l}+1, \ldots, \check{x}_{r}-1\right\}\right] .
\end{aligned}
$$

The expected policy loss terms $E\left[v\left(x_{i}, d\right)\right]$ and $E\left[v\left(x_{i}, \gamma\right)\right]$ are specified in (4) and (5) in the main text, respectively. Relating ( $A 1)$ and $(A 2)$ and rearranging yields the best response entry strategy (3) in the main text.

With parties, if all citizens $j \neq i$ are using cutpoint strategy $(A 1)$, then the expected payoff of a citizen type $x_{i}$ in the Right Party for entering the political competition, $\check{e}_{i}=1$, is given by (and analogous for a citizen in the Left Party)

$$
\begin{aligned}
& E\left[\pi_{i} \mid x_{i}, \check{e}_{i}=1\right]=(1-p)^{n-1} b \\
& +\sum_{m_{r}=2}^{n}\left(\begin{array}{c}
n-1 \\
m_{r}-1
\end{array}\right)\left(\frac{p}{2}\right)^{m_{r}-1}(1-p)^{n-m_{r}}\left[\frac{b}{m_{r}}-\frac{m_{r}-1}{m_{r}} E\left[v\left(x_{i}, \gamma\right) \mid \gamma \in\left\{\check{x}_{r}, \ldots, 100\right\}\right]\right] \\
& +\sum_{m_{l}=1}^{n-1} \sum_{k=0}^{n-m_{l}-1}\left(\begin{array}{c}
n-1 \\
m_{l}
\end{array}\right)\left(\frac{p}{2}\right)^{m_{l}}(1-p)^{n-m_{l}-1}\left(\begin{array}{c}
n-m_{l}-1 \\
k
\end{array}\right)\left(\frac{1}{2}\right)^{n-m_{l}-1} \\
& \quad \times\left[\rho_{r} b-\left(1-\rho_{r}\right) E\left[v\left(x_{i}, \gamma\right) \mid \gamma \in\left\{1, \ldots, \check{x}_{l}\right\}\right]\right]
\end{aligned}
$$




$$
\begin{aligned}
& +\sum_{m_{r}=2}^{n-1} \sum_{m_{l}=1}^{n-m_{r}} \sum_{k=0}^{n-m}\left(\begin{array}{c}
n-1 \\
m_{r}-1
\end{array}\right)\left(\begin{array}{c}
n-m_{r} \\
m_{l}
\end{array}\right)\left(\frac{p}{2}\right)^{m_{r}-1}\left(\frac{p}{2}\right)^{m_{l}}(1-p)^{n-m}\left(\begin{array}{c}
n-m \\
k
\end{array}\right)\left(\frac{1}{2}\right)^{n-m} \\
& \quad \times\left[-\left(1-\rho_{r}\right) E\left[v\left(x_{i}, \gamma\right) \mid \gamma \in\left\{1, \ldots, \check{x}_{l}\right\}\right]+\rho_{r}\left[\frac{b}{m_{r}}-\frac{m_{r}-1}{m_{r}} E\left[v\left(x_{i}, \gamma\right) \mid \gamma \in\left\{\check{x}_{r}, \ldots, 100\right\}\right]\right]\right]-c
\end{aligned}
$$

and her expected payoff from not entering, $\check{e}_{i}=0$, is given by

$$
\begin{aligned}
& E\left[\pi_{i} \mid x_{i}, \check{e}_{i}=0\right]=(1-p)^{n-1}\left[\frac{b}{n}-\frac{n-1}{n} E\left[v\left(x_{i}, d\right) \mid d \in\left\{\check{x}_{l}+1, \ldots, \check{x}_{r}-1\right\}\right]\right] \\
& -\sum_{m_{r}=2}^{n}\left(\begin{array}{c}
n-1 \\
m_{r}-1
\end{array}\right)\left(\frac{p}{2}\right)^{m_{r}-1}(1-p)^{n-m_{r}} E\left[v\left(x_{i}, \gamma\right) \mid \gamma \in\left\{\check{x}_{r}, \ldots, 100\right\}\right] \\
& -\sum_{m_{l}=1}^{n-1}\left(\begin{array}{c}
n-1 \\
m_{l}
\end{array}\right)\left(\frac{p}{2}\right)^{m_{l}}(1-p)^{n-m_{l}-1} E\left[v\left(x_{i}, \gamma\right) \mid \gamma \in\left\{1, \ldots, \check{x}_{l}\right\}\right] \\
& -\sum_{m_{r}=2}^{n-1} \sum_{m_{l}=1}^{n-m_{r} n-m-1} \sum_{k=0}^{n-1}\left(\begin{array}{c}
n-1 \\
m_{r}-1
\end{array}\right)\left(\begin{array}{c}
n-m_{r} \\
m_{l}
\end{array}\right)\left(\frac{p}{2}\right)^{m_{r}-1}\left(\frac{p}{2}\right)^{m_{l}}(1-p)^{n-m}\left(\begin{array}{c}
n-m \\
k
\end{array}\right)\left(\frac{1}{2}\right)^{n-m} \\
& \times\left[\left(1-\rho_{r}\right) E\left[v\left(x_{i}, \gamma\right) \mid \gamma \in\left\{1, \ldots, \check{x}_{l}\right\}\right]+\rho_{r} E\left[v\left(x_{i}, \gamma\right) \mid \gamma \in\left\{\check{x}_{r}, \ldots, 100\right\}\right]\right] .
\end{aligned}
$$

The three expected policy loss terms $E\left[v\left(x_{i},.\right)\right]$ with parties are specified in (7) to (9) and the win

probability of the Right Party, $\rho_{r}$, is described on p. 10 in the main text. Then, relating both conditions and rearranging yields the best response entry strategy (6) in the main text.

\section{Average expected welfare}

Without parties, the ex-ante (i.e., before citizen ideal points are randomly drawn), the average or expected individual payoff $\pi_{e}=\frac{1}{n} \sum_{i=1}^{n} \pi_{e, i}$ is given by

$$
\begin{aligned}
& \pi_{e, N o \text { Party }}=K-p c+\frac{b}{n}-(1-p)^{n} \frac{n-1}{n} \sum_{x=\check{x}_{l}+1}^{\check{x}_{r}-1} \sum_{\gamma=\check{x}_{l}+1}^{\check{x}_{r}-1} \frac{|x-\gamma|}{\left(\check{x}_{r}-\check{x}_{l}-1\right)^{2}}-\sum_{m=1}^{n}\left(\begin{array}{c}
n \\
m
\end{array}\right) p^{m}(1-p)^{n-m} \\
& \times \frac{1}{n}\left[(n-m) \sum_{x=\check{x}_{l}+1}^{\check{x}_{r}-1} \sum_{\gamma=1}^{\check{x}_{l}} \frac{|x-\gamma|}{\left(\check{x}_{r}-\check{x}_{l}-1\right) \check{x}_{l}}+(m-1) \cdot \frac{1}{2}\left(\sum_{x=1}^{\check{x}_{l}} \sum_{\gamma=1}^{\check{x}_{l}} \frac{|x-\gamma|}{\left(\check{x}_{l}\right)^{2}}+\sum_{x=1}^{\check{x}_{l}} \sum_{\gamma=\check{x}_{r}}^{100} \frac{|x-\gamma|}{\left(\check{x}_{l}\right)^{2}}\right)\right]
\end{aligned}
$$

and with parties it is given by

$\pi_{e, \text { Party }}=K-s c+\frac{b}{n}-(1-p)^{n} \cdot \frac{n-1}{n} \sum_{x=\check{x}_{l}+1}^{\check{x}_{r}-1} \sum_{\gamma=\check{x}_{l}+1}^{\check{x}_{r}-1} \frac{|x-\gamma|}{\left(\check{x}_{r}-\check{x}_{l}-1\right)^{2}}$ 
$-2 \sum_{m_{l}=1}^{n}\left(\begin{array}{c}n \\ m_{l}\end{array}\right)\left(\frac{p}{2}\right)^{m_{l}}(1-p)^{n-m_{l}} \cdot \frac{1}{n}\left[\left(n-m_{l}\right) \sum_{x=\check{x}_{l}+1}^{\check{x}_{r}-1} \sum_{\gamma=1}^{\check{x}_{l}} \frac{|x-\gamma|}{\left(\check{x}_{r}-\check{x}_{l}-1\right) \check{x}_{l}}+\left(m_{l}-1\right) \sum_{x=1}^{\check{x}_{l}} \sum_{\gamma=1}^{\check{x}_{l}} \frac{|x-\gamma|}{\left(\check{x}_{l}\right)^{2}}\right]$

$-\sum_{m_{l}=1}^{n-1} \sum_{m_{r}=1}^{n-m_{l}} \sum_{k=0}^{n-m}\left(\begin{array}{c}n \\ m_{l}\end{array}\right)\left(\begin{array}{c}n-m_{l} \\ m_{r}\end{array}\right)\left(\frac{p}{2}\right)^{m_{l}}\left(\frac{p}{2}\right)^{m_{r}}(1-p)^{n-m}\left(\begin{array}{c}n-m \\ k\end{array}\right)\left(\frac{1}{2}\right)^{n-m}$

$\times \frac{1}{n}\left[\rho_{l}\left(k \sum_{x=\check{x}_{l}+1}^{50} \sum_{\gamma=1}^{\check{x}_{l}} \frac{|x-\gamma|}{\left(50-\check{x}_{l}\right) \check{x}_{l}}+(n-m-k) \sum_{x=51}^{\check{x}_{r}-1} \sum_{\gamma=1}^{\check{x}_{l}} \frac{|x-\gamma|}{\left(50-\check{x}_{l}\right) \check{x}_{l}}+\left(m_{l}-1\right) \sum_{x=1}^{\check{x}_{l}} \sum_{\gamma=1}^{\check{x}_{l}} \frac{|x-\gamma|}{\left(\check{x}_{l}\right)^{2}}\right.\right.$

$\left.+m_{r} \sum_{x=\check{x}_{r}}^{100} \sum_{\gamma=1}^{\check{x}_{l}} \frac{|x-\gamma|}{\left(\check{x}_{l}\right)^{2}}\right)+\left(1-\rho_{l}\right)\left(k \sum_{x=\check{x}_{l}+1}^{50} \sum_{\gamma=\check{x}_{r}}^{100} \frac{|x-\gamma|}{\left(50-\check{x}_{l}\right) \check{x}_{l}}+(n-m-k) \sum_{x=51}^{\check{x}_{r}-1} \sum_{\gamma=\check{x}_{r}}^{100} \frac{|x-\gamma|}{\left(50-\check{x}_{l}\right) \check{x}_{l}}\right.$

$\left.\left.+m_{l} \sum_{x=1}^{\check{x}_{l}} \sum_{\gamma=\check{x}_{r}}^{100} \frac{|x-\gamma|}{\left(\check{x}_{l}\right)^{2}}+\left(m_{r}-1\right) \sum_{x=\check{x}_{r}}^{100} \sum_{\gamma=\check{x}_{r}}^{100} \frac{|x-\gamma|}{\left(\check{x}_{l}\right)^{2}}\right)\right]$,

where $\rho_{l}=H\left[\frac{m_{l}+k}{n}-\frac{1}{2}\right]$ is the Left Party's probability of winning and $H[z]=\left\{\begin{array}{cll}0 & \text { if } & z<0 \\ 1 / 2 & \text { if } & z=0 \\ 1 & \text { if } & z>0\end{array}\right.$.

\section{QRE entry conditions}

Here, we derive the logit QRE conditions of entry probabilities, allowing for erroneous binary decisions at each ideal point $x \in\{1,2, \ldots 100\}$. If $\lambda=0$, then each citizen type $x$ makes purely random decisions (i.e., enters with probability one-half). If $\lambda \approx \infty$, then everyone follows the BNE cutpoint strategy. Since there are one-hundred different citizen types $x$, we must simultaneously solve onehundred conditions. Without parties, the QRE condition for a citizen type $x_{i}$ is given by

$$
q_{x_{i}}=\frac{1}{1+e^{-\lambda V\left(x_{i}, \vec{q}_{x}\right)}}
$$

The LHS gives her entry probability $q_{x_{i}}$ and on $R H S \vec{q}_{x}$ denotes the vector of entry probabilities of all feasible types $x \in\{1,2, \ldots, 100\}$ that every other citizen $j \neq i$ may possess. Since ideal points are iid random draws from a uniform distribution, each $x$ occurs with probability $1 / 100$ so the average entry probability of each other citizen $j$ is given by

$$
q=\frac{1}{100} \sum_{x=1}^{100} q_{x}
$$


Further, RHS contains citizen i's expected net payoff from entering (cf. (3) in the main text), which is given by

$$
\begin{aligned}
V\left(x_{i}, \vec{q}_{x}\right)=(1-q)^{n-1}\left(\frac{n-1}{n}\right)\left[b+E\left[v\left(x_{i}, d\right) \mid d \in\{1, \ldots, 100\}\right]\right] \\
+\sum_{m=2}^{n}\left(\begin{array}{c}
n-1 \\
m-1
\end{array}\right) q^{m-1}(1-q)^{n-m} \frac{1}{m}\left[b+E\left[v\left(x_{i}, \gamma\right) \mid \gamma \in\{1, \ldots, 100\}\right]\right]-c,
\end{aligned}
$$

with

and

$$
E\left[v\left(x_{i}, d\right) \mid d \in\{1, \ldots, 100\}\right]=\frac{1}{1-q} \sum_{x=1}^{100}\left(1-q_{x}\right) \frac{\left|x_{i}-x\right|}{100}
$$

$$
E\left[v\left(x_{i}, \gamma\right) \mid \gamma \in\{1, \ldots, 100\}\right]=\frac{1}{q} \sum_{x=1}^{100} q_{x} \frac{\left|x_{i}-x\right|}{100}
$$

where the expected policy losses $(A 11)$ and ( $A 12)$ account for all feasible ideal points of others (i.e., not just those of the more extreme entrants as dictated by the BNE cutpoint pair).

Then, for a given $\lambda$ the one-hundred equilibrium conditions of the form (A8) are simultaneously solved for $x=1, \ldots, 100$ to determine the QRE vector of entry probabilities, $\vec{q}_{x}^{\lambda}$.

Next, with parties we need to distinguish between entrants from the Left and Right Party, respectively, so we replace the average entry probability of each other citizen $j(A 9)$ by the probabilities that $j$ enters from the left or right direction, respectively:

$$
q_{l}=\frac{1}{50} \sum_{x=1}^{50} q_{x}
$$

and

$$
q_{r}=\frac{1}{50} \sum_{x=51}^{100} q_{x}
$$

where the average individual entry probability is

$$
q=q_{l}+q_{r}
$$

The $R H S$ of (A8) contains citizen i's expected net payoff from entering (cf. (6) in the main text), which for a right type $x \in\{51, \ldots, 100\}$ is given by (and similar for a left type $x \in\{1, \ldots, 50\}$ )

$$
\begin{aligned}
& V\left(x_{i}, \vec{q}_{x}\right)=(1-q)^{n-1}\left(\frac{n-1}{n}\right)\left[b+E\left[v\left(x_{i}, d\right) \mid d \in\{1, \ldots, 100\}\right]\right]+ \\
& \quad+\sum_{m_{r}=2}^{n}\left(\begin{array}{c}
n-1 \\
m_{r}-1
\end{array}\right)\left(q_{r}\right)^{m_{r}-1}(1-q)^{n-m_{r}} \cdot \frac{1}{m_{r}}\left[b+E\left[v\left(x_{i}, \gamma\right) \mid \gamma \in\{51, \ldots, 100\}\right]\right]
\end{aligned}
$$




$$
\begin{aligned}
&+\sum_{m_{l}=1}^{n-1} \sum_{k=0}^{n-m_{l}-1}\left(\begin{array}{c}
n-1 \\
m_{l}
\end{array}\right)\left(q_{l}\right)^{m_{l}}(1-q)^{n-m_{l}-1}\left(\begin{array}{c}
n-m_{l}-1 \\
k
\end{array}\right)\left(\frac{1}{2}\right)^{n-m_{l}-1} \\
& \times \rho_{r}\left[b+E\left[v\left(x_{i}, \gamma\right) \mid \gamma \in\{1, \ldots, 50\}\right]\right] \\
&+\sum_{m_{r}=2} \sum_{m_{l}=1}^{n-1} \sum_{k=0}^{n-m_{r}}\left(\begin{array}{c}
n-1 \\
m_{r}-1
\end{array}\right)\left(\begin{array}{c}
n-m_{r} \\
m_{l}
\end{array}\right)\left(q_{r}\right)^{m_{r}-1}\left(q_{l}\right)^{m_{l}}(1-q)^{n-m}\left(\begin{array}{c}
n-m \\
k
\end{array}\right)\left(\frac{1}{2}\right)^{n-m} \\
& \quad \times \frac{\rho_{r}}{m_{r}}\left[b+E\left[v\left(x_{i}, \gamma\right) \mid \gamma \in\{51, \ldots, 100\}\right]\right]-c
\end{aligned}
$$

with

$$
\begin{gathered}
\left.E\left[v\left(x_{i}, d\right) \mid d \in\{1, \ldots, 100\}\right]\right]=\frac{1}{1-q} \sum_{x=1}^{100}\left[1-q_{x}\right] \frac{\left|x_{i}-x\right|}{100} \\
E\left[v\left(x_{i}, \gamma\right) \mid \gamma \in\{51, \ldots, 100\}\right]=\frac{1}{q_{r}} \sum_{x=51}^{100} q_{x} \frac{\left|x_{i}-x\right|}{50}
\end{gathered}
$$

and

$$
E\left[v\left(x_{i}, \gamma\right) \mid \gamma \in\{1, \ldots, 50\}\right]=\frac{1}{q_{l}} \sum_{x=51}^{100} q_{x} \frac{\left|x_{i}-x_{j}\right|}{50}
$$

where he expected policy losses (A17) to (A18) account for all feasible ideal points of others, and $\rho_{r}=H\left[\frac{m_{r}+k}{n}-\frac{1}{2}\right]$ gives the win probability of the Right Party with $H[z]=\left\{\begin{array}{cll}0 & \text { if } & z<0 \\ 1 / 2 & \text { if } & z=0 . \text { Then, } \\ 1 & \text { if } & z>0\end{array}\right.$ for a given $\lambda$ the one-hundred equilibrium conditions of the form $(A 8)$ are simultaneously solved for $x=1, \ldots, 100$ to determine the QRE vector of entry probabilities, $\vec{q}_{x}^{\lambda}$.

Figure A1: QRE distributions of entry probabilities - Example

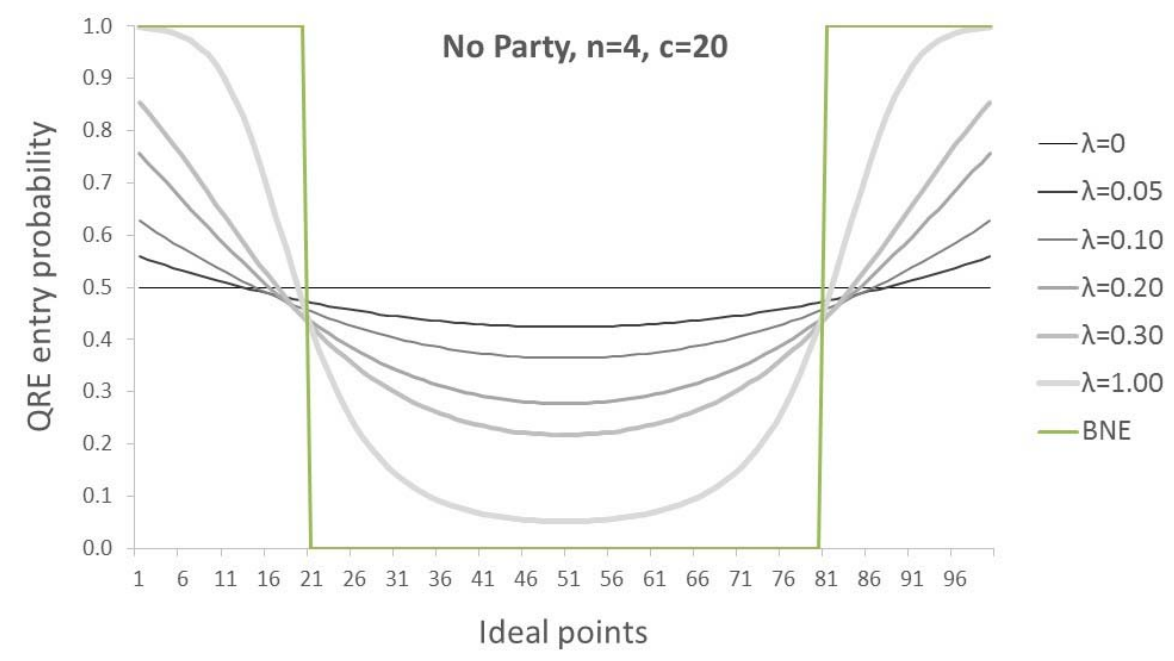




\section{Appendix B: Supplementary Tables and Figures}

Table B1: Entry rates - Predictions and data

\begin{tabular}{rrr|rrr}
$n$ & $c$ & Party & \multicolumn{1}{|c}{$p^{o b s}$} & $p^{*}\left(p_{\text {emp }}^{*}\right)$ & $p^{\hat{\lambda}}\left(p_{\text {emp }}^{\hat{\lambda}}\right)$ \\
\hline 4 & 10 & No & .687 & $.840(.844)$ & $.603(.602)$ \\
4 & 10 & Yes & .673 & $.680(.671)$ & $.569(.570)$ \\
4 & 20 & No & .560 & $.400(.417)$ & $.457(.459)$ \\
4 & 20 & Yes & .496 & $.340(.364)$ & $.434(.436)$ \\
10 & 10 & No & .519 & $.420(.426)$ & $.465(.465)$ \\
10 & 10 & Yes & .445 & $.280(.256)$ & $.424(.423)$ \\
10 & 20 & No & .426 & $.200(.181)$ & $.331(.330)$ \\
10 & 20 & Yes & .321 & $.160(.152)$ & $.303(.302)$
\end{tabular}

Note: Standard errors of $p^{o b s}$ are all in the range $[.013, .016]$. BNE is indicated by an asterisk and QRE by $\hat{\lambda}$, the maximum likelihood estimate of the degree of error.

Table B2: Average payoffs - Predictions and data

\begin{tabular}{rrr|ccc}
$n$ & $c$ & Party & $\bar{\pi}^{\text {obs }}$ & $\pi_{e}^{*}\left(\pi_{e m p}^{*}\right)$ & $\pi_{e}^{\hat{\lambda}}\left(\pi_{e m p}^{\hat{\lambda}}\right)$ \\
\hline 4 & 10 & No & 69.26 & $66.98(67.00)$ & $69.91(70.67)$ \\
4 & 10 & Yes & 70.42 & $69.09(69.06)$ & $71.96(72.14)$ \\
4 & 20 & No & 64.22 & $64.59(64.00)$ & $66.65(66.95)$ \\
4 & 20 & Yes & 68.03 & $66.69(66.56)$ & $68.41(68.73)$ \\
10 & 10 & No & 64.44 & $59.71(60.28)$ & $65.45(65.01)$ \\
10 & 10 & Yes & 68.31 & $61.24(63.98)$ & $68.36(68.31)$ \\
10 & 20 & No & 62.61 & $57.59(59.25)$ & $63.20(63.24)$ \\
10 & 20 & Yes & 64.35 & $59.90(61.89)$ & $65.94(65.91)$
\end{tabular}

Note: Standard errors for $\bar{\pi}^{o b s}$ are in the range [.71,.82].

Table B3: Average payoffs, policy losses, and entry expenses - Predictions and data

\begin{tabular}{|c|c|c|c|c|c|c|c|c|c|c|c|c|}
\hline \multicolumn{3}{|c|}{ Treatment } & \multicolumn{3}{|c|}{ Payoffs } & \multicolumn{3}{|c|}{ Policy losses } & \multicolumn{3}{|c|}{ Entry expenses } & Bonus \\
\hline$n$ & $c$ & Party & $\bar{\pi}^{o b s}$ & $\bar{\pi}_{e m p}^{*}$ & $\bar{\pi}_{e m p}^{\widehat{\lambda}}$ & $\bar{v}^{o b s}$ & $\bar{v}_{e m p}^{*}$ & $\bar{v}_{e m p}^{\widehat{\lambda}}$ & $p^{o b s} c$ & $p_{e m r}^{*}$ & $p_{e m p}^{\widehat{\lambda}} c$ & $b / n$ \\
\hline 4 & 10 & No & 69.26 & 67.00 & 70.67 & 25.12 & 25.81 & 24.55 & 6.87 & 8.44 & 6.02 & 1.25 \\
\hline 4 & 10 & Yes & 70.42 & 69.06 & 72.14 & 24.10 & 25.48 & 23.41 & 6.73 & 6.71 & 5.70 & 1.25 \\
\hline 4 & 20 & No & 64.22 & 64.00 & 66.95 & 25.83 & 28.91 & 25.12 & 11.20 & 8.33 & 9.18 & 1.25 \\
\hline 4 & 20 & Yes & 68.03 & 66.56 & 68.73 & 23.30 & 27.42 & 23.81 & 9.92 & 7.27 & 8.71 & 1.25 \\
\hline 10 & 10 & No & 64.44 & 60.28 & 65.01 & 30.87 & 35.96 & 30.84 & 5.19 & 4.26 & 4.65 & 0.50 \\
\hline 10 & 10 & Yes & 68.31 & 63.98 & 68.31 & 27.74 & 33.96 & 27.96 & 4.45 & 2.56 & 4.23 & 0.50 \\
\hline 10 & 20 & No & 62.61 & 59.25 & 63.24 & 29.38 & 37.63 & 30.66 & 8.52 & 3.62 & 6.60 & 0.50 \\
\hline 10 & 20 & Yes & 64.35 & 61.89 & 65.91 & 29.74 & 35.58 & 28.56 & 6.42 & 3.03 & 6.04 & 0.50 \\
\hline
\end{tabular}

Note: Standard errors for $\bar{\pi}^{o b s}$ are in the range [.71,.82], and for $\bar{v}^{o b s}$ and $p^{o b s} c$ they are in the range $[.69, .80]$ and $[.13, .34]$, respectively. 
Table B4: Observed average payoffs, policy losses, and entry expenses of leaders and non-leaders

\begin{tabular}{crrr|lrrr} 
Leader & $n$ & $c$ & Party & $\bar{\pi}^{\text {obs }}$ & $\bar{v}^{\text {obs }}$ & \multicolumn{1}{c}{${ }^{o b s} c$} & $b$ \\
\hline \multirow{6}{*}{ No } & 4 & 10 & No & 60.65 & 33.49 & 5.86 & - \\
& 4 & 10 & Yes & 62.23 & 32.13 & 5.64 & - \\
& 4 & 20 & No & 57.19 & 34.44 & 8.37 & - \\
& 4 & 20 & Yes & 61.88 & 31.07 & 7.06 & - \\
& 10 & 10 & No & 61.04 & 34.30 & 4.66 & - \\
& 10 & 10 & Yes & 65.34 & 30.82 & 3.84 & - \\
& 10 & 20 & No & 60.12 & 32.64 & 7.24 & - \\
& 10 & 20 & Yes & 62.00 & 33.04 & 4.96 & - \\
\hline \multirow{6}{*}{ Yes } & 4 & 10 & No & 95.11 & 0 & 9.89 & 5 \\
& 4 & 10 & Yes & 95.00 & 0 & 10.00 & 5 \\
& 4 & 20 & No & 85.30 & 0 & 19.70 & 5 \\
& 4 & 20 & Yes & 86.50 & 0 & 18.50 & 5 \\
& 10 & 10 & No & 95.00 & 0 & 10.00 & 5 \\
& 10 & 10 & Yes & 95.08 & 0 & 9.92 & 5 \\
& 10 & 20 & No & 85.00 & 0 & 20.00 & 5 \\
& 10 & 20 & Yes & 85.50 & 0 & 19.50 & 5
\end{tabular}

Note: For non-leaders, standard errors of $\bar{\pi}^{o b s}, \bar{v}^{o b s}$, and $p^{o b s} c$ are in the range [.74,.98], [.70,.89], and $[.15, .36]$, respectively. For leaders, standard errors of $\bar{\pi}^{o b s}$ and $p^{o b s} c$ are both in the range $[.00, .34]$.

Figure B1: Entry rates per ideal points for normalized distances to median ideal point -

Predictions and data

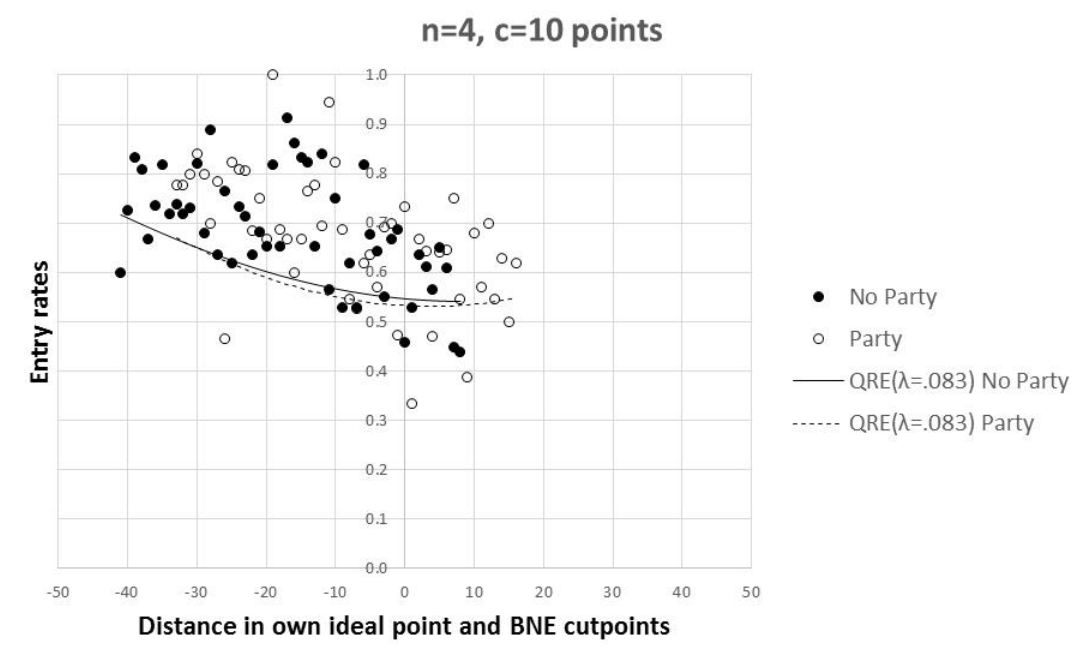



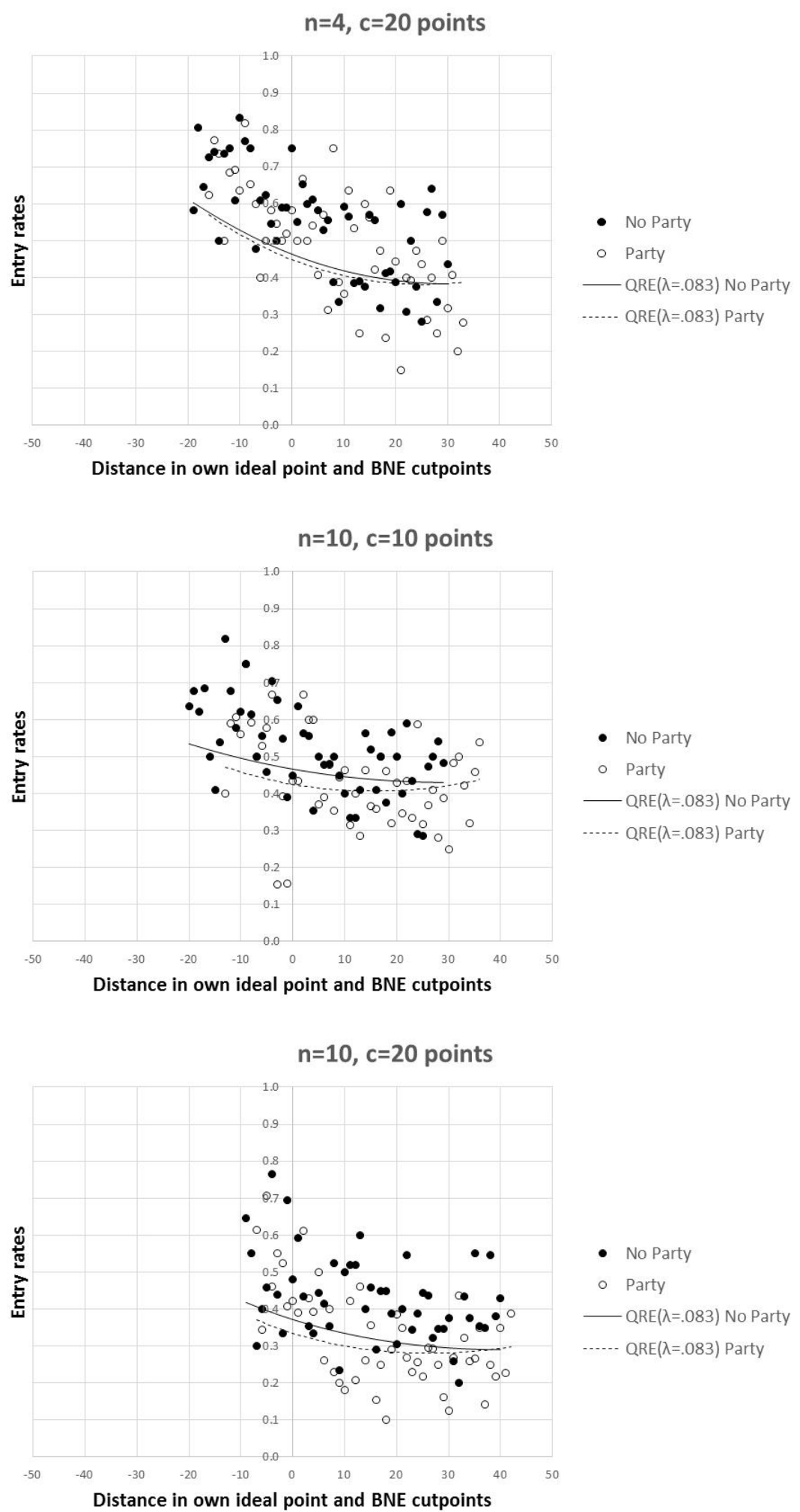
Figure B2: Frequency of participants with ideal points $\{51, \ldots, 100\}$
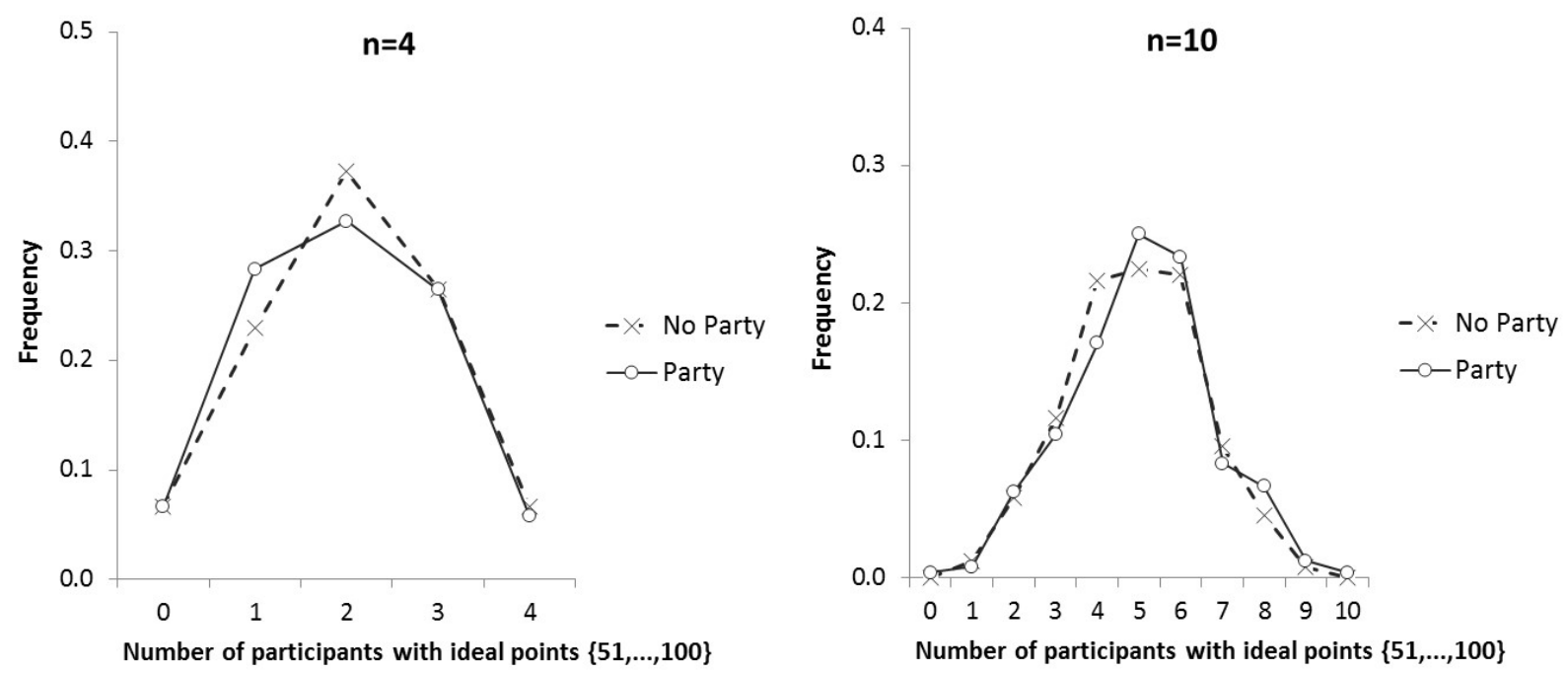

Figure B3: Cumulative frequency distributions of average individual entry rates
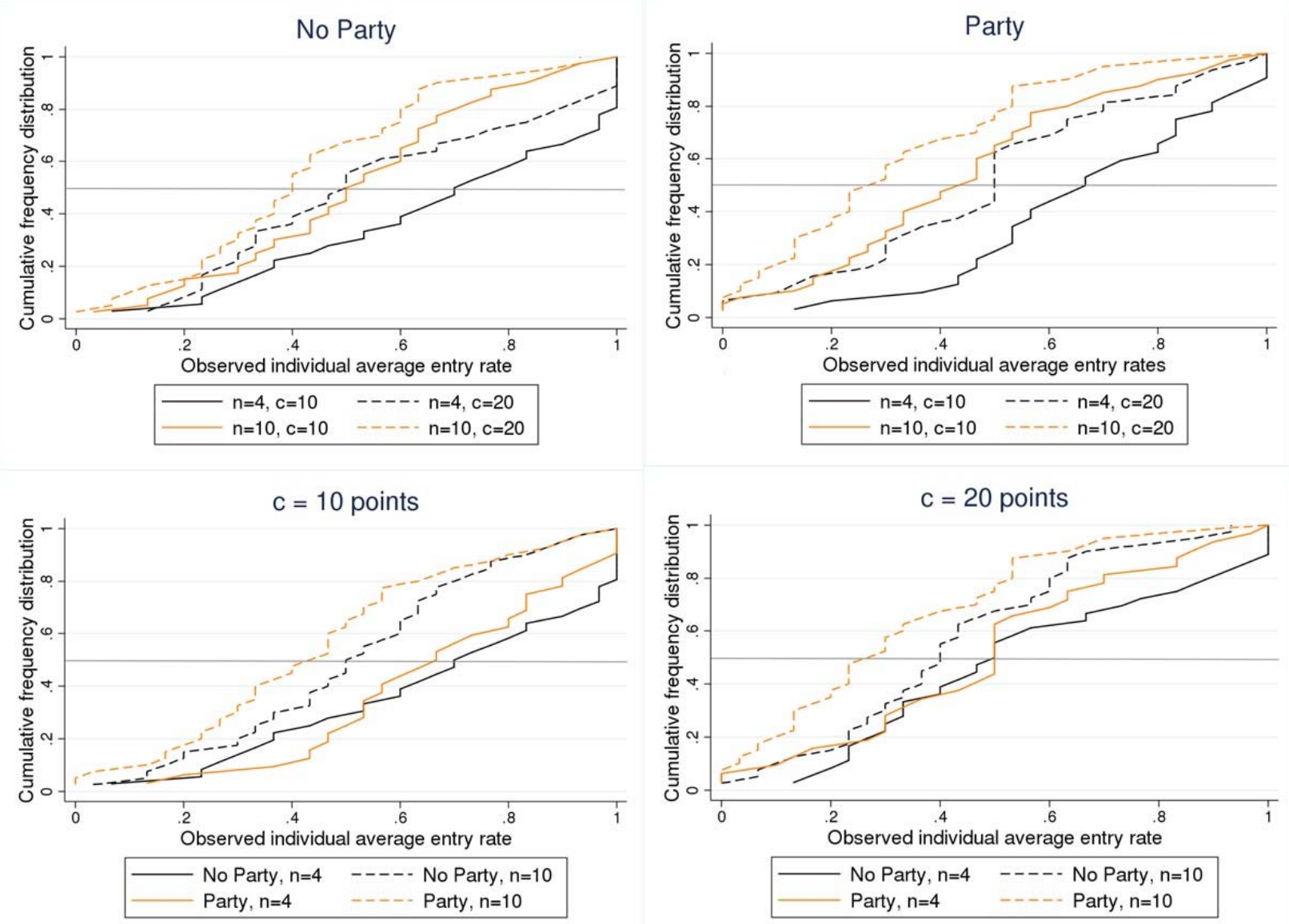
Figure B4: Cumulative frequency distributions of estimated individual cutpoint pairs
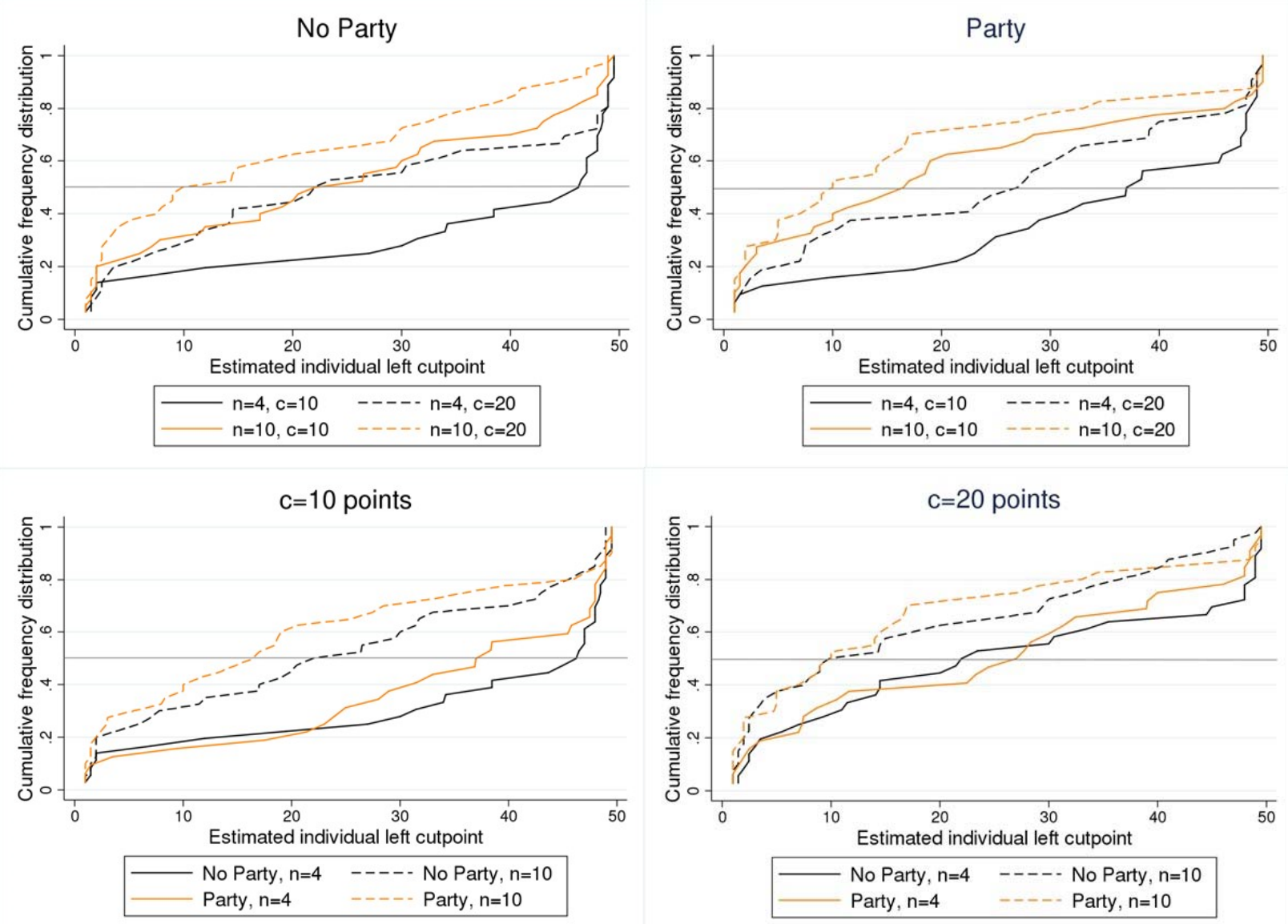


\section{Online supporting material}

Sample Instructions (Party, $n=4, c=10$ )

\section{Instructions}

Thank you for agreeing to participate in this decision-making experiment. You will receive \$7 for participating, plus additional earnings during the experiment that depend on your own decisions, the decisions of others, and chance. Your earnings in the experiment are expressed in points. 250 points are worth $\$ 1$. At the end of the experiment, your total earnings in points will be exchanged into dollars and paid to you in cash. No other participant will be informed about your payment!

Please switch offyour cellphone, remain quiet, and do not communicate with other participants during the entire experiment! Raise your hand if you have any questions, and one of us will come to you to answer them.

\section{Parts and Decision Rounds}

The experiment consists of two parts, labeled Part 1 and Part 2. Each part has 30 decision rounds. We will read you the instructions for Part 1 now. After completing Part 1 we will read instructions for Part 2.

\section{Your Group}

\section{Instructions Part 1}

At the beginning of each round, all participants will be randomly divided into groups of 4. Thus, in addition to yourself, there will be three other members in your group. Note that you will not know who these other members are. Also, please note that the groups are completely independent of each other. In any particular round you will have no interaction at all with participants in the other groups.

\section{Group Decision Problem}

In each round, your group will decide on a group outcome, which can be any integer between 1 and 100. This is done by electing a group leader, whose best outcome will be implemented as the group outcome. Each of you will be told what your own best outcome is in that round, and different group members will generally have different best outcomes. You receive the highest benefits if the group outcome equals your own best outcome, and receive lower benefits the further the group outcome is from your own best outcome. We will explain the exact payoff details shortly.

\section{Random Assignment of Best Outcomes}

How is your own best outcome assigned in a round? This is done by the computer. It will randomly assign each member in your group a best outcome by choosing one of the integers from 1 to 100 , with each integer being equally likely. The computer does this completely independently for each group member, so typically different members will each have a different best outcome. You are only told your own best outcome. You are not told the best outcome of any other group member. Therefore, knowing your own best outcome gives you no information whatsoever about anybody else's best outcome. All you know about another group member's best outcome is that it is some integer from 1 to 100, with an equal chance of being any of those integers. Importantly, best outcomes are reassigned independently in each round, so your own best outcome will typically vary from round to round, and your past assigned best outcomes have nothing to do with your future assigned best outcomes. 


\section{Low Number and High Number Members}

If your best outcome is 50 or less, then we refer to you as a "Low number" member. If your best outcome is $\mathbf{5 1}$ or greater, then we refer to you as a "High number" member. The same holds for the other members in your group.

\section{Decision-Making Stages}

Each round consists of two decision-making stages, labeled Stage 1 and Stage 2.

\section{Stage 1}

Each group member will decide on whether or not to enter as a candidate in the upcoming election for group leader of the current round. Whoever will become the group leader receives a bonus of 5 points. However, if you choose to enter as a candidate for leadership, then you must pay an entry fee of 10 points. If you choose not to enter, then you do not pay any fee ( 0 points). The winner of the election will be the group leader, and the group outcome coincides with her or his best outcome.

\section{Stage 2}

In this stage, if more than one low number member entered in Stage 1, then the computer will randomly select one of them for the election with an equal chance for each. This selected member is called "Low Number Candidate." Similarly, if more than one high number member entered in Stage 1 , then the computer will randomly select one of them for the election with an equal chance for each. This selected member is called "High Number Candidate." Each group member casts a single vote for exactly one candidate. The candidates are indicated on the computer screen, represented by decision buttons labeled with their member ID label letter and whether they are from Low or High. For example, if member $X$ and member $Q$ are the respective low and high number candidates, then there will be two decision buttons with labels "Low Number Candidate X" and "High Number Candidate Q", respectively. If no low (high) number member entered in Stage 1, then there is no low (high) number candidate.

Each group member, whether a candidate or not, then votes for one of the candidates by clicking on the respective decision button, possibly for her- or himself. If you are a candidate yourself, then the label on your decision button is highlighted in red. The candidate with the most votes in your group is the elected group leader. If the candidates have the same number of votes, then one of them will be randomly selected as the group leader, with an equal chance for each.

Special case: If no group member entered as a candidate in Stage 1, then there is no voting. Instead, one of the four group members will be randomly selected as the group leader, with an equal chance for each. Please note that this randomly selected group leader does not pay the entry fee (because she or he actually did not enter) but nonetheless still receives the leader bonus of 5 points and the group outcome equals her or his best outcome.

It is important to remember that the group outcome is always exactly equal to the best outcome of the group leader, regardless of whether she or he entered and won the election or was selected randomly after nobody entered.

\section{Your Round Earnings}


Your round earnings will depend on three factors: the distance between your own best outcome and the group outcome, whether you chose to enter the election as a candidate, and whether you are the group leader. There are only four possibilities:

(i) You were a candidate but not elected to be group leader

In this case, your round earnings equal " 100 points minus the absolute distance between your own best outcome and the group outcome, minus the 10 points entry fee" or:

$$
\begin{aligned}
& \text { Your round earnings (candidate, but not group leader) } \\
& \qquad=100-\mid \text { your best outcome }- \text { group outcome } \mid-10 .
\end{aligned}
$$

Example: Your own best outcome is 60 , and the group outcome is 91, then your round earnings are $100-|60-91|-10=59$ points.

(ii) You were a candidate and elected to be group leader

In this case, your round earnings are equal to exactly 95 points, or:

$$
\begin{aligned}
& \text { Your round earnings (candidate and group leader) } \\
& \qquad \begin{array}{l}
=100-\mid \text { your best outome }- \text { group outcome } \mid+5-10 \\
=100-0+5-10=95 .
\end{array}
\end{aligned}
$$

(iii) You were not a candidate and were not the group leader

In this case, your round earnings equal " 100 points minus the absolute distance between your own best outcome and the group outcome" or:

$$
\begin{aligned}
& \text { Your round earnings (neither candidate nor group leader) } \\
& \qquad=100-\mid \text { your best outcome - group outcome } \mid
\end{aligned}
$$

Example: Your own best outcome is 60 , and the group outcome is 15 , then your round earnings are $100-|60-15|=55$ points.

(iv) Nobody entered as a candidate and you were randomly selected to be group leader

In this case, your round earnings are equal to exactly 105 points, or:

$$
\begin{aligned}
& \text { Your round earnings (not candiate, but group leader) } \\
& \qquad \begin{array}{l}
=100-\mid \text { your best outome }- \text { group outcome } \mid+5 \\
=100-0+5=105 .
\end{array}
\end{aligned}
$$

Observe that if you are a candidate, your expected round payoff is highest if you vote for yourself. This is because in case you will be elected group leader, you receive the leader bonus of 5 points and avoid any losses in points from the absolute difference between your best outcome and the group outcome, as your best outcome will be the group outcome.

Note that your total earnings in Part 1 are equal to the sum of all your round earnings in that part.

Each of the 30 decision rounds in Part 1 will follow the rules just described. Remember that you are randomly re-matched into new 4-person groups and randomly reassigned your own best outcomes between each round. At the bottom of your computer screen there will be a full summary of the history of your experience and payoffs in all prior rounds. 
Decision screens (Party, $n=4, c=10$ points)

\section{Entry decision}

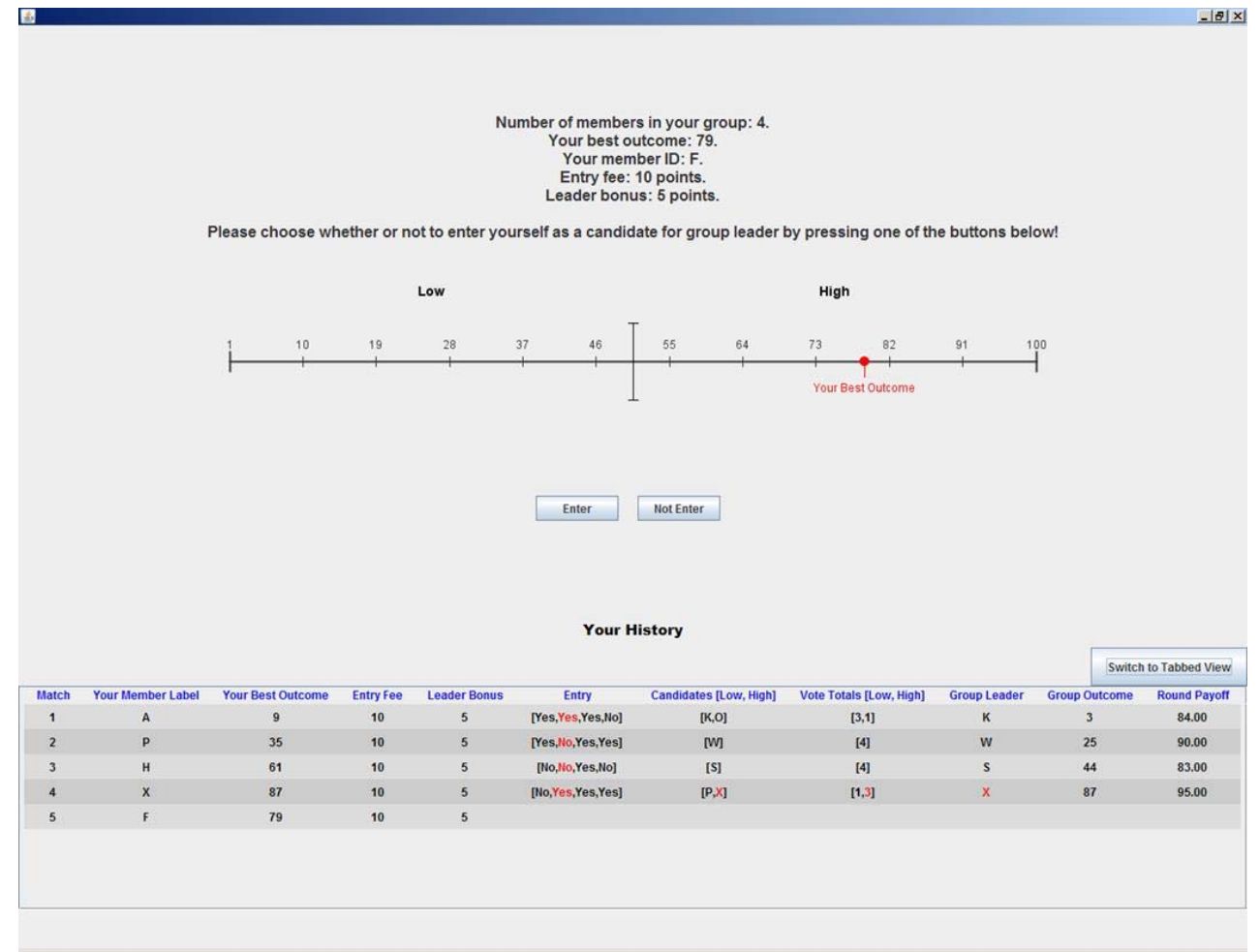

Voting decision

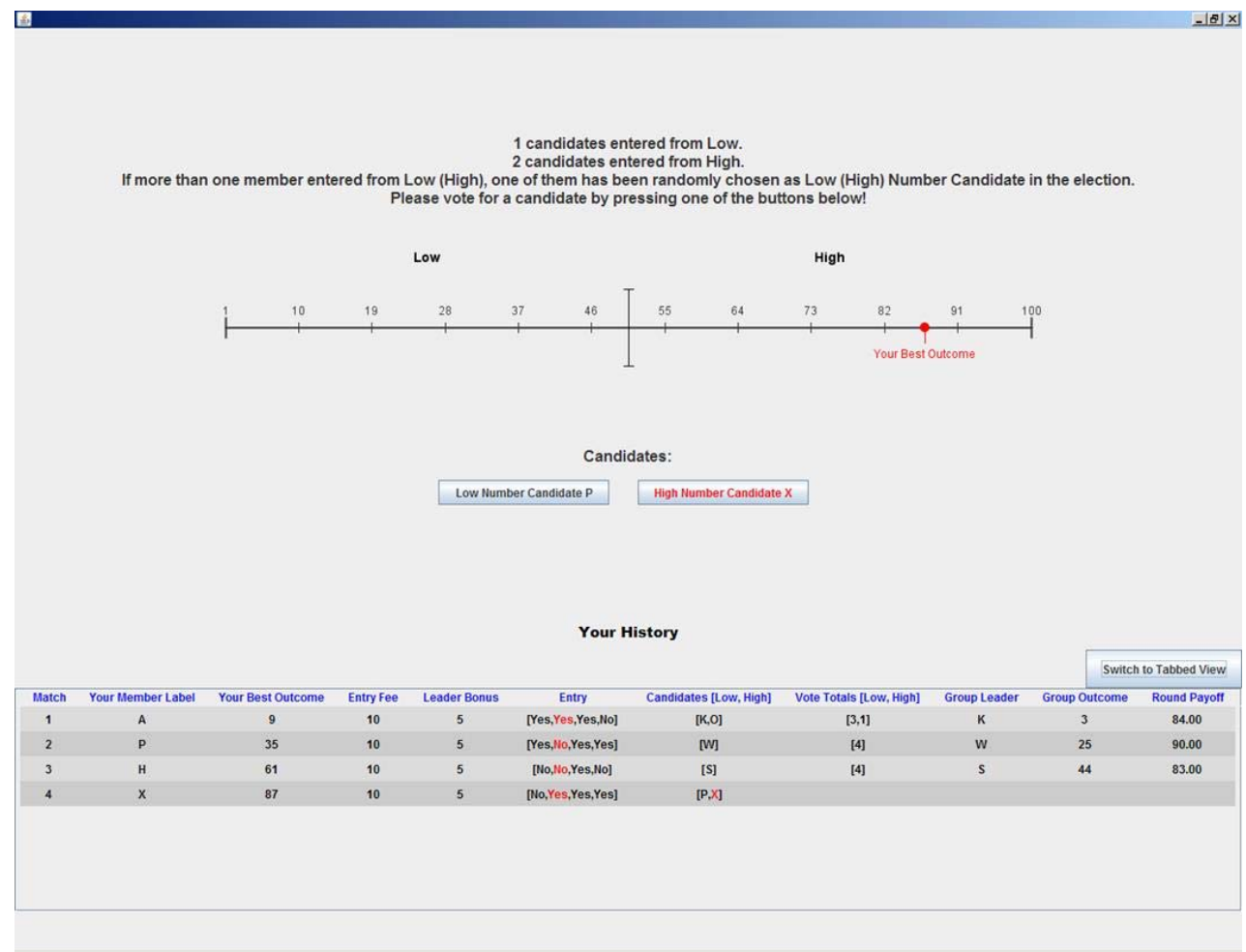




\section{Election results}

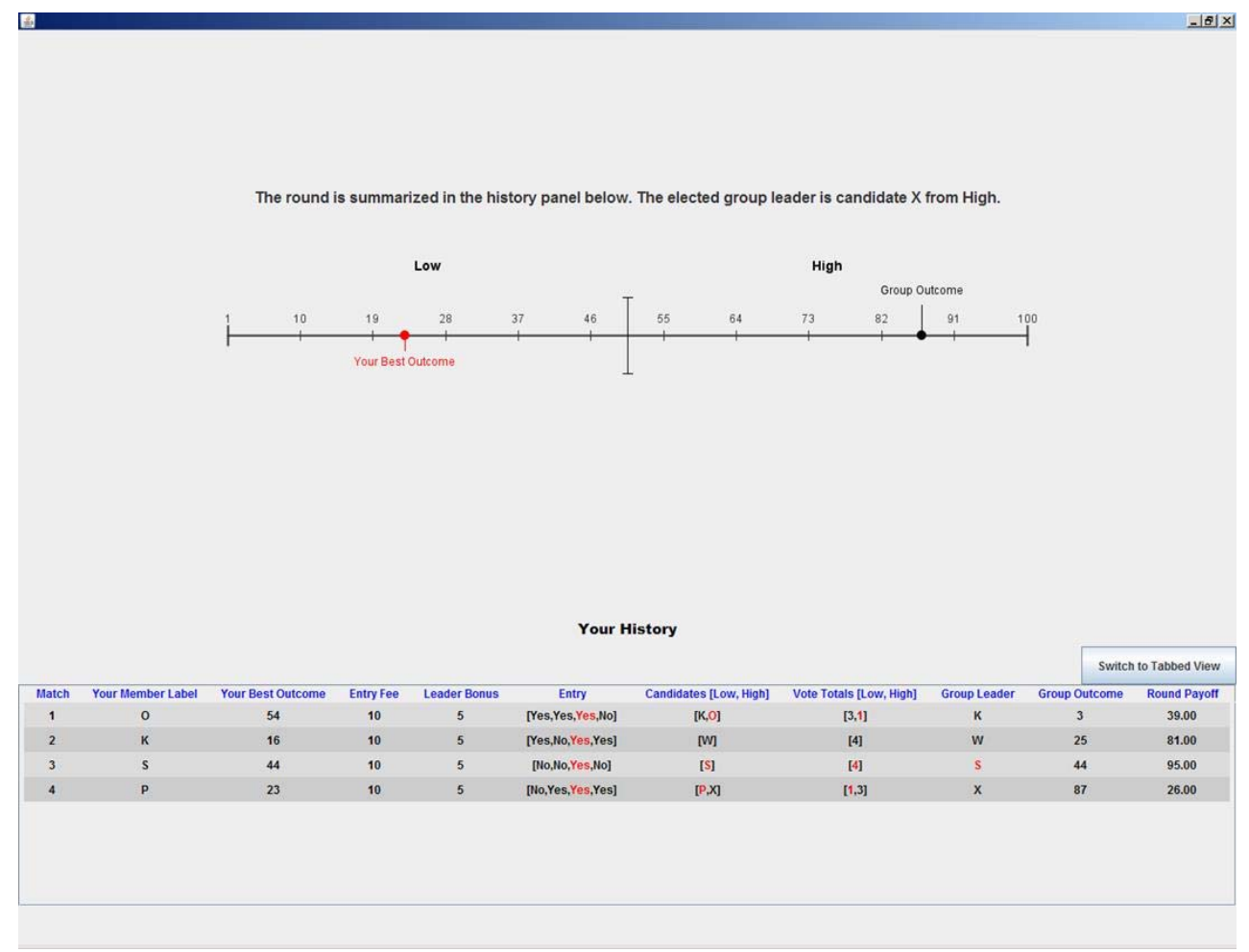


Decision screens (No Party, $n=10, c=10$ points)

\section{Entry decision}

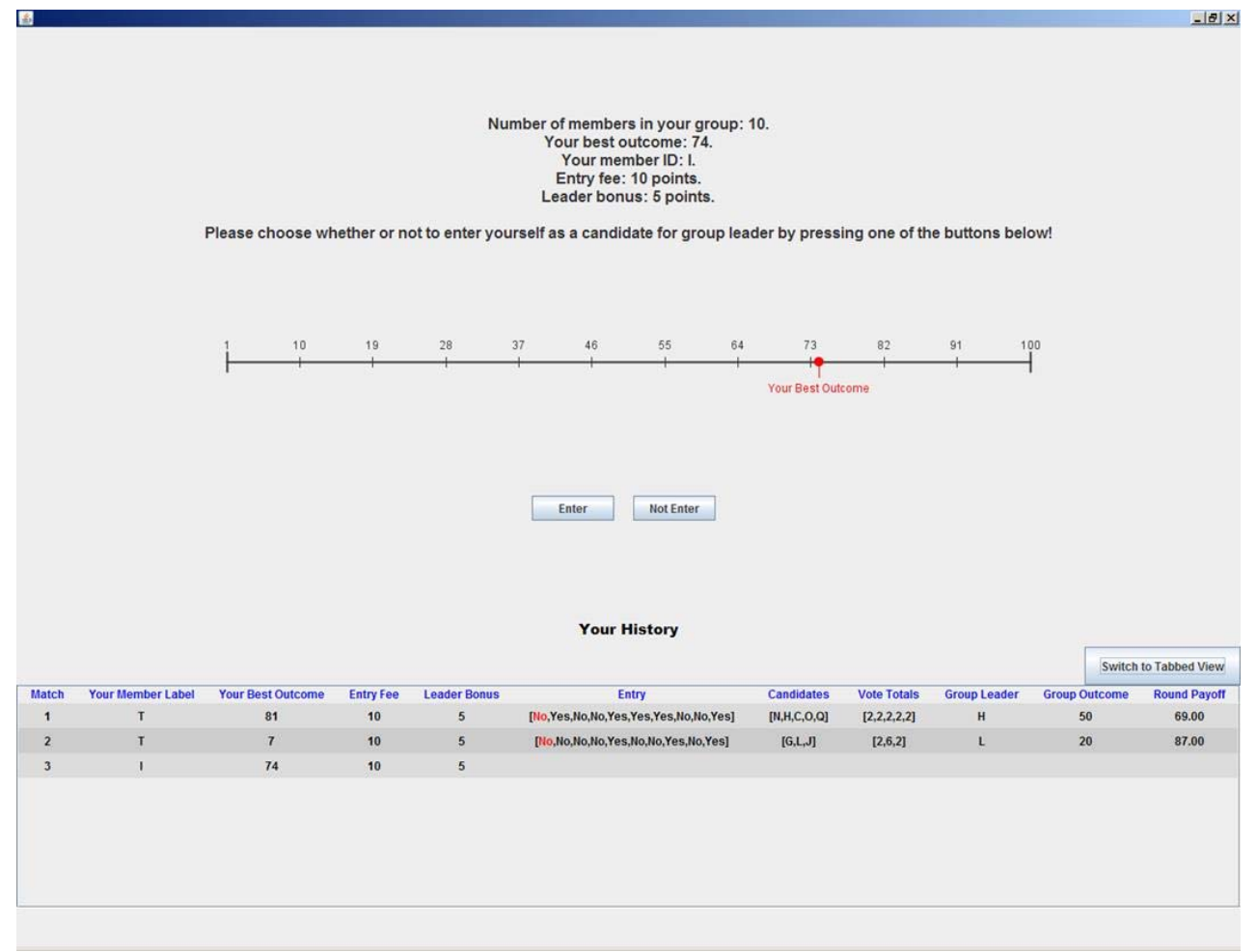

\section{Voting decision}

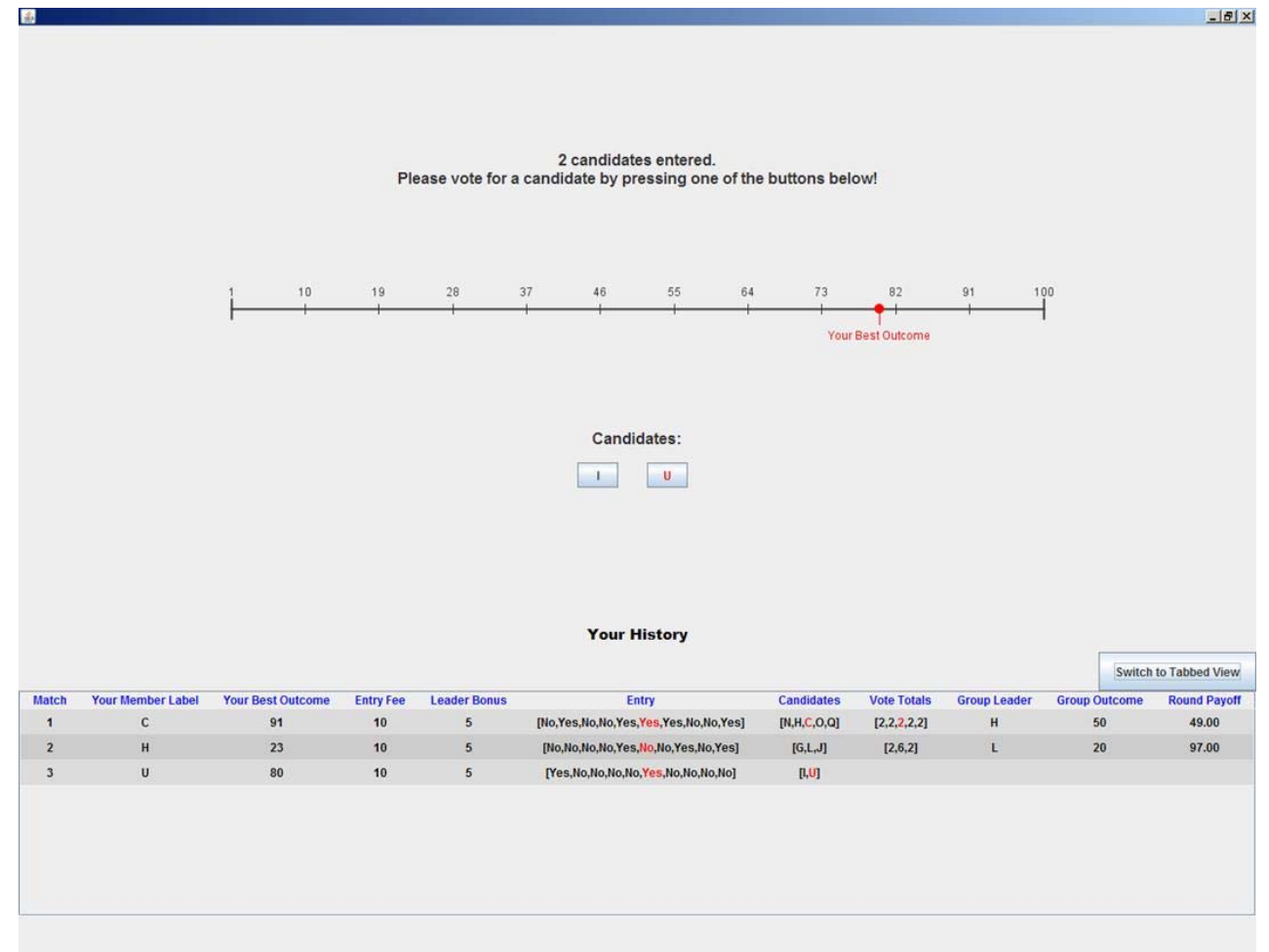




\section{Election results}

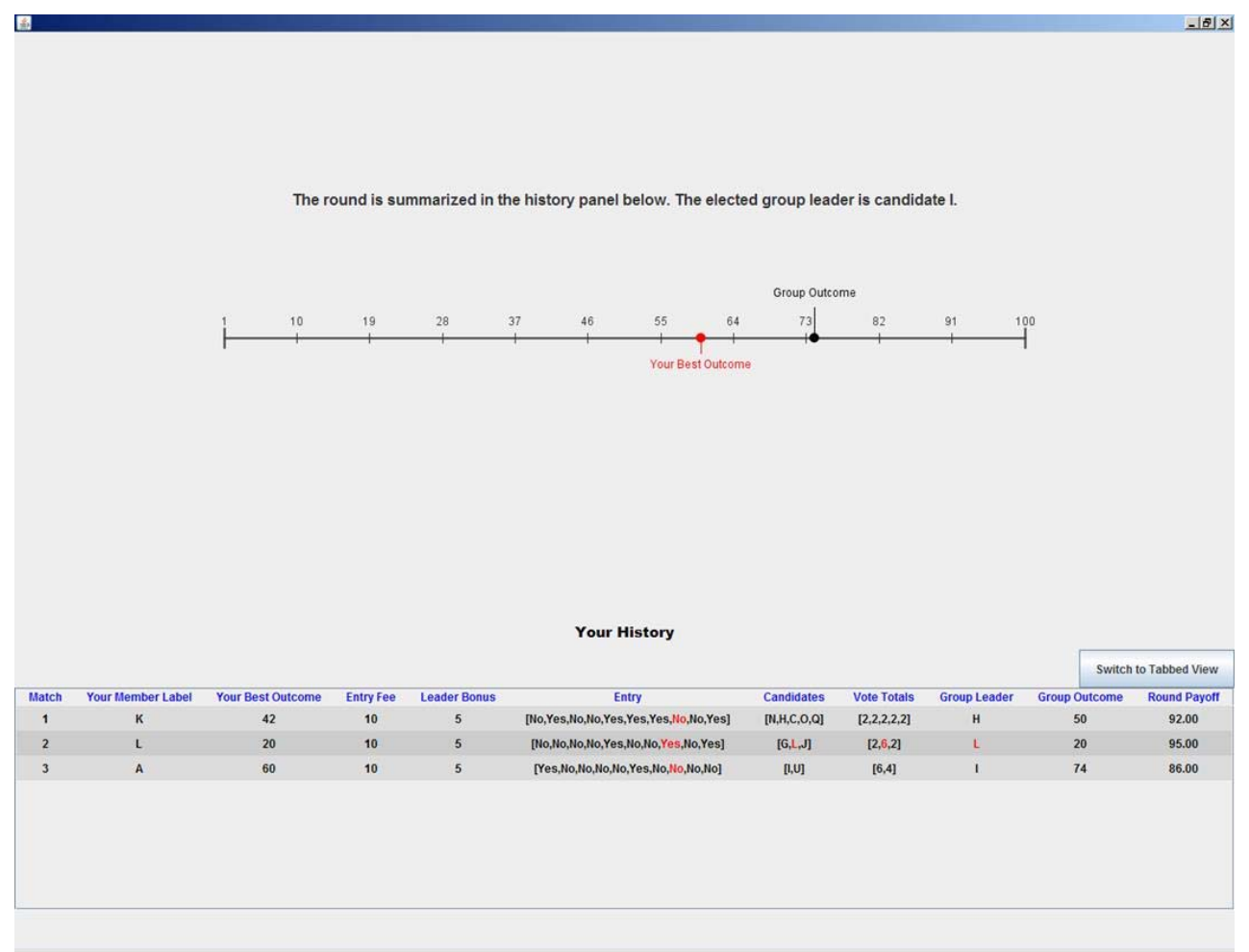

